\title{
Thermal transmittance of lightweight steel framed walls: experimental versus numerical and analytical approaches
}

\author{
Paulo Santos $^{1 *}$, Margarida Gonçalves ${ }^{1}$, Cláudio Martins ${ }^{1}$, Nelson Soares ${ }^{1,2}$, José J. Costa ${ }^{2}$ \\ ${ }^{1}$ ISISE, Department of Civil Engineering, University of Coimbra, Pólo II, Rua Luís Reis Santos, 3030 -788 Coimbra, \\ Portugal \\ ${ }^{2}$ ADAI, LAETA, Department of Mechanical Engineering, University of Coimbra, Pólo II, Rua Luís Reis Santos, \\ 3030-788 Coimbra, Portugal \\ * Correspondent author: Paulo Santos, pfsantos@dec.uc.pt
}

\begin{abstract}
Given the great influence of the thermal transmittance of the building envelope on the overall thermal performance and energy efficiency of the building, it is essential to accurately determine the $U$-value of the main building envelope elements. Due to the great heterogeneity of the thermal conductivity of the elements presented in a lightweight steelframed (LSF) wall, and to the geometric complexity of some steel framed structures, a reliable estimation of the thermal transmittance of LSF elements is even more challenging. Indeed, thermal bridging originated by steel studs must be considered in the assessment of the thermal transmittance of LSF walls. In this work, the thermal transmittance ( $U$-value) of three LSF walls with different configurations will be investigated based on four different approaches: experimental laboratorial measurements based on the Heat Flow Meter (HFM) method; 3D finite element method (FEM) simulations using ANSYS CFX ${ }^{\circledR}$ software; 2D FEM-based simulations using THERM software; analytical estimations based on the ISO 6946 procedure for building components with inhomogeneous layers. Several verification procedures were performed to ensure the reliability of the results. It was found that a secondary wood stud can mitigate the thermal bridging effect of the steel frame and improve the LSF thermal performance, which is more noticeable when there is no thermal insulation. Furthermore, a good agreement was found between the results of the 2D FEM and the analytical ISO 6946 approaches for the LSF wall with only vertical steel studs.
\end{abstract}

Keywords: Lightweight steel framing, LSF walls, Thermal transmittance, $U$-value, Experimental measurements, Numerical simulations, Analytical approach. 


\section{Introduction}

Nowadays, energy is one of the main concerns of our society, and the buildings' sector is a key-player representing approximately $40 \%$ of the total energy consumption and $c a$. $36 \%$ of $\mathrm{CO}_{2}$ emissions in Europe [1]. In fact, the buildings' sector is the largest single energy consumer in the European Union (EU), having huge potential for energy efficiency gains since $75 \%$ of the building stock is considered energy inefficient. Moreover, $35 \%$ of the EU's buildings are over 50 years old [1]. Therefore, there is a need to refurbish and replace old and energy inefficient buildings by new ones with innovative solutions and improved performance.

Given its economical, functional and environmental advantages, lightweight steel-framed (LSF) construction is gaining market share, particularly for low-rise residential buildings, relatively to traditional concrete structure and masonry brick walls construction [2] [3]. As described by Soares et al. [3], LSF construction presents several advantages, such as: small weight with high mechanical strength; speed of construction and reduced disruption on-site; great potential for recycling and reuse; high architectural flexibility for retrofitting purposes; easy prefabrication allowing modular construction, suited to the economy of mass production; economy in transportation and handling; superior quality, precise tolerances and high standards achieved by off-site manufacture control; excellent stability of shape in case of humidity; and resistance to insect damage. Despite these advantages, the low thermal mass of LSF construction (and resulting low thermal inertia) may be problematic for some functioning conditions and climates, leading to several comfort-related problems [4] [5], such as overheating and larger temperature fluctuations. Kendrick et al. [6] suggested that lightweight construction may lead to higher indoor temperatures during summer, particularly in the warmer future scenarios, due to the lack of thermal mass. Rodrigues et al. [7] also pointed out the problem of summer overheating 
in a low-energy steel-framed house regarding warmer scenarios. Overheating may also lead to higher cooling energy demand. The improvement of the thermal mass/inertia could be very useful to boost thermal comfort of occupants and to increase the thermal behaviour and energy efficiency of buildings in climates with higher daily thermal amplitudes [8]. Another drawback of LSF construction is related with the higher risk of thermal bridges due to the higher thermal conductivity of the steel framing elements. Thermal bridging originated by steel studs is seen as a hot topic of research in the LSF construction research field. Roque and Santos [9] studied the effectiveness of thermal insulation in LSF walls regarding its position in the assemblage. They concluded that external thermal insulation is more effective than batt insulation. More recently, these authors have also evaluated the sound insulation of LSF façade walls and the importance of the insulation position [10]. It was concluded that, although batt insulation is not the most efficient location from the thermal performance perspective, it is necessary to ensure good sound insulation. Santos et al. [11] evaluated the importance of flanking thermal losses on the thermal performance of an LSF wall. They confirmed that flanking heat loss must be taken into account, not only in laboratorial tests or numerical simulations but also in real buildings, given the lateral heat exchange with the adjacent construction. Later on, they performed a parametric study to evaluate the effectiveness of several strategies for mitigating thermal bridges [12]. They demonstrated that the thermal transmittance of the tested LSF wall could be reduced by up to $8.3 \%$, corresponding to $75 \%$ of the total impact of the steel thermal bridges.

The energy efficiency and thermal behaviour of LSF buildings also depend on other factors, such as: climatic conditions [13], thermal inertia [14], level of thermal insulation [15], and ventilation rates [16]. Santos et al. [17] performed a parametric study to evaluate the thermal performance of LSF residential buildings in Csb climatic regions. They 
evaluated the influence of several parameters, such as: ventilation rate, thermal insulation level, overhangs shading, windows shading devices and windows glazing; and they concluded that the parameters with more influence during the cooling season were the overhangs and the ventilation.

Given its relevance for the building energy balance, it is essential to accurately determine the thermal transmittance ( $U$-value) of the elements of the building envelope (e.g. walls, slabs and roofs). Due to the great heterogeneity of the LSF elements and to the geometric complexity of some steel framed structures, a reliable estimation of the $U$-value of LSF elements is even more difficult to achieve [3]. There are several methods to measure the thermal behaviour and $U$-value of building components in-situ or in laboratory controlled conditions. Soares et al. [18] provided a state-of-the-art review on laboratory and in-situ non-destructive methods to evaluate the thermal transmittance and behaviour of walls, windows, and construction elements with innovative materials. The most widely used technique to determine the $U$-value of an envelope element is the Heat Flow Meter (HFM) method [19], which can be applied in-situ [20] or under controlled laboratorial conditions [11]. For reliable measurements, this method requires a significant temperature difference between both sides of the assessed element and an unidirectional heat flux, i.e., perpendicular to the wall surface [19]. To overcome these constraints, one of the most suitable laboratorial techniques for implementing the HFM method to assess the thermal performance of full-size LSF or other strongly non-homogeneous construction elements is the Hot Box (HB) apparatus [21], which can be Guarded HB (GHB) or Calibrated HB (CHB). Another technique that could be useful to support the HFM method in heterogeneous building elements (e.g. LSF walls [11]) is the Infrared Thermography (IRT). Besides its qualitatively use, IRT could also be used to quantitatively determine the thermal transmittance of building elements [22]. 
Gorgolewski [23] developed a simplified analytical method to calculate the thermal transmittance of LSF walls. This method was similar in principle to that prescribed by ISO 6946 [24] but adapted to increase accuracy. The obtained mean error was less than $3 \%$ with a maximum error of $8 \%$. Zalewski et al. [25] make use of experimental measurements and numerical simulations to characterize the thermal performance of a prefabricated LSF wall, including the influence of thermal bridges. The studied wall was evaluated in experimental lab cells and measurements of heat flux and surface temperatures were performed at different locations of the wall. The experimental results were used to validate a numerical 3D finite element model. The overall $U$-value of this LSF wall was then obtained using the results of validated model. Li et al. [26] evaluated the thermal and energy performance of a LSF-bamboo composite wall structure on a testing residential building. They performed field measurements and numerical simulations and they concluded that the steel-bamboo wall has a higher thermal performance in comparison with common wall structures in winter. More recently, Atsonios et al. [27] proposed two new methods for the in-situ measurement of the overall thermal transmittance of cold frame LSF walls. These new in-situ measurement methods were denominated Representative Points Method (RPM) and Weighted Area Method (WAM). In both methods, the point thermal bridges due to screws and fasteners were not taken into account. The RPM method is based on the assumption that the heat flow on specific points at the internal surface of the examined wall is always equal to the averaged heat flow of the whole surface, while the WAM method is based on the ASHRAE Zone Method concept [28]. Both methods combine an infrared thermography analysis with the recording and processing of indoor/outdoor air temperature and heat flux measurements. Both theoretical and experimental validation were performed. The authors obtained a very good accuracy, with an error lower than $5 \%$. 
In this paper, the thermal transmittance of three LSF walls with different configurations is investigated using four different approaches: $(i)$ experimental laboratorial measurements based on the HFM method; (ii) 3D FEM-based simulations using ANSYS CFX ${ }^{\circledR}$ software; (iii) 2D FEM-based simulations using THERM software; (iv) analytical estimations based on the ISO 6946 [24] approach for building components with inhomogeneous layers. Firstly, the tested LSF walls are described and the used materials are characterized. Then, the experimental apparatus and test procedures are presented, followed by the presentation of the 3D and 2D FEM-based numerical models (including the domain discretization, the description of the boundary conditions, the modelling of air spaces and the verification of the models' accuracy). Next, the ISO 6946 [24] analytical approach is explained and its accuracy verified. Afterwards, the obtained results for the thermal transmittance of the evaluated LSF walls are presented. 


\section{Walls description and material characterization}

The evaluated LSF walls are modular and the steel structure of a single module $(1.20 \mathrm{~W} \times$ $2.50 \mathrm{H}[\mathrm{m}])$ is presented in Figure 1. In this work, three different LSF wall configurations are investigated, as illustrated in Figure 2, in order to evaluate the relevance of the bridged batt thermal insulation and the continuous exterior thermal insulation. Moreover, a $100 \mathrm{~mm}$-thick homogeneous XPS wall panel was tested to verify the accuracy of the experimental measurements, since the thermal conductivity of the XPS material is known a priori $\left(0.036 \mathrm{~W} /\left(\mathrm{m} \cdot{ }^{\circ} \mathrm{C}\right)\right)$.

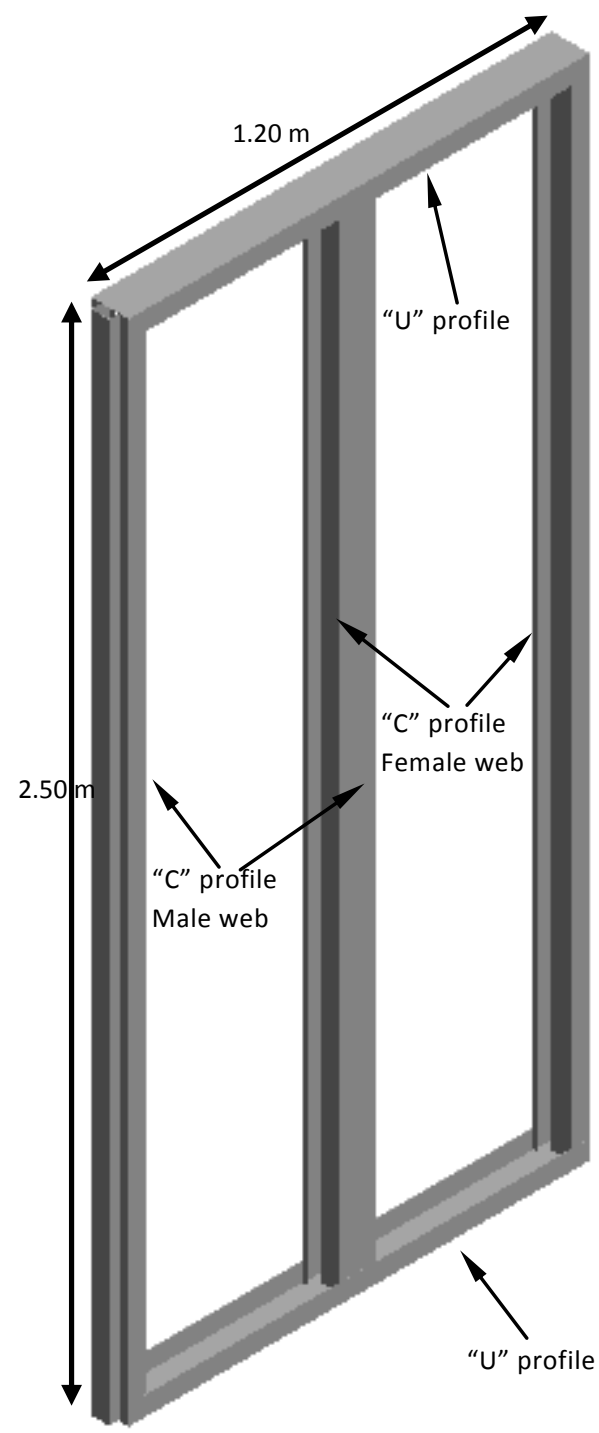

(a) Steel frame perspective
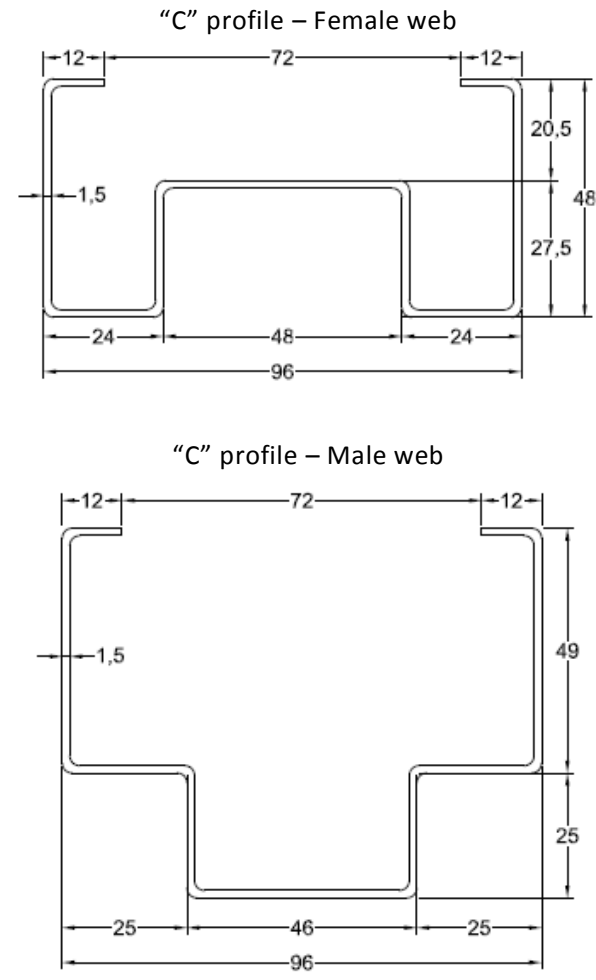

"U" profile

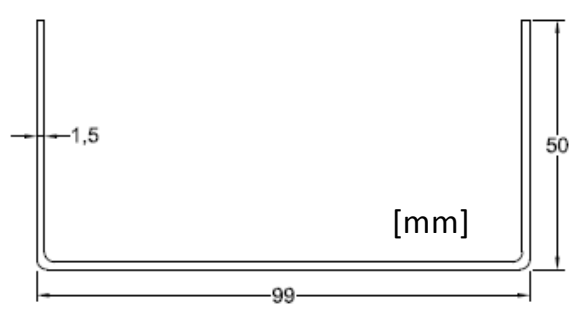

(b) Steel studs cross-sections

Figure 1. Steel structure of a LSF module. 


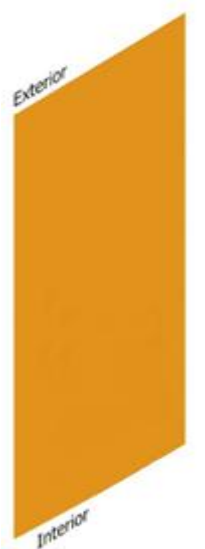

(a)

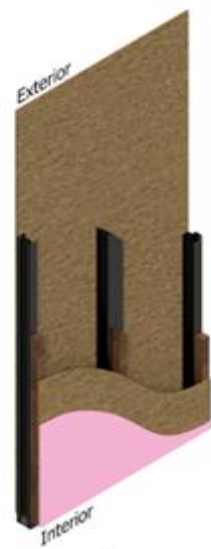

(b)

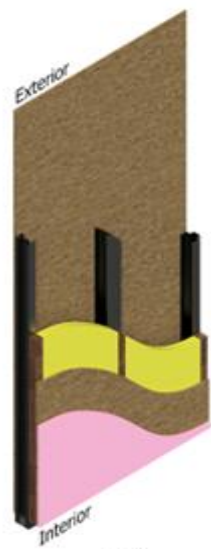

(c)

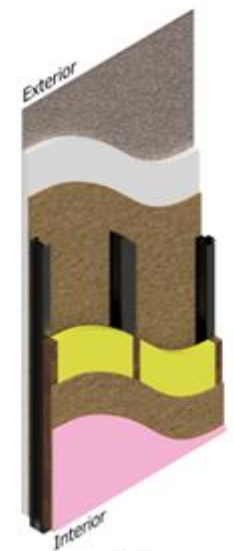

(d)
EETICS finish

EPS (ETICS)

EosB

Steel studs

Wood frame

Mineral wool

Gypsum board

WPS

Figure 2. Evaluated walls - (a) homogeneous XPS panel; heterogeneous LSF walls: (b) without thermal insulation (LSF wall n.1); (c) with mineral wool (MW) in the air-cavity (LSF wall n. 2); (d) with MW in the air-cavity and ETICS (LSF wall n.3).

The first LSF wall configuration (Figure 2b) has no thermal insulation. From the inner side, there is a wood frame on the steel structure, where the OSB and a gypsum plasterboard panels are jointly attached. On the exterior side, the OSB panel is directly attached to the steel frame. In the second LSF wall configuration (Figure 2c), the inner space between wood studs was filled with a $50 \mathrm{~mm}$-thick layer of mineral wool (MW). The third LSF wall (Figure 2d) is provided with an external thermal insulation composite system (ETICS) composed by an EPS thermal insulation layer and a finishing mortar layer. The value of the thermal conductivity considered for each material is the one listed in the datasheet of each materials or taken from standard databases. Table 1 presents the thickness of each layer and the thermal conductivity of each material.

Table 1. Thickness and thermal conductivity of the materials used.

\begin{tabular}{lcc}
\hline Material & $\boldsymbol{d}[\mathrm{mm}]$ & $\boldsymbol{\lambda}\left[\mathrm{W} /\left(\mathrm{m} \cdot{ }^{\circ} \mathrm{C}\right)\right]$ \\
\hline Gypsum board & 15 & 0.250 \\
OSB & 12 & 0.130 \\
Wood frame & 50 & 0.180 \\
Mineral wool & 50 & 0.037 \\
XPS & 100 & 0.036 \\
Steel studs & 96 & 61.0 \\
OSB & 12 & 0.130 \\
ETICS (EPS) & 60 & 0.040 \\
ETICS finish & 4 & 0.750 \\
\hline
\end{tabular}

$d$ - Thickness; $\lambda$ - Thermal conductivity; OSB - Oriented Strand Board; XPS - Extruded Polystyrene; EPS - Expanded Polystyrene; ETICS - Exterior Thermal Insulation Coating System. 
The fasteners used to assemble the steel structure and to attach the wood slats, the OSB and the gypsum plasterboard to the steel frame are steel self-drilling screws. These screws will be neglected in the numerical simulations since their contribution to thermal bridging is reduced. Their relevance to the overall $U$-value of LSF wall is also low, as previously verified in refs. [9] [27]. Moreover, given the very reduced thickness of the vapour barrier (about $0.2 \mathrm{~mm}$ ) and its consequent negligible influence in wall $U$-value, it was adopted not to use it in the experimental lab tests, neither in the numerical simulations. 


\section{Experimental lab tests}

\subsection{Experimental setup}

The laboratorial experiments were performed using the HB apparatus (Figure 3) which was designed and assembled following the prescriptions provided by ISO 8990 [21]. This equipment allows evaluating the thermal performance of walls at real-scale testspecimens, up to $3.6 \mathrm{~W} \times 2.7 \mathrm{H} \times 0.4 \mathrm{~T}[\mathrm{~m}]$. It was used as a set of two climatic chambers, hot and cold boxes and the thermal performance of the walls was measured using the HFM method.

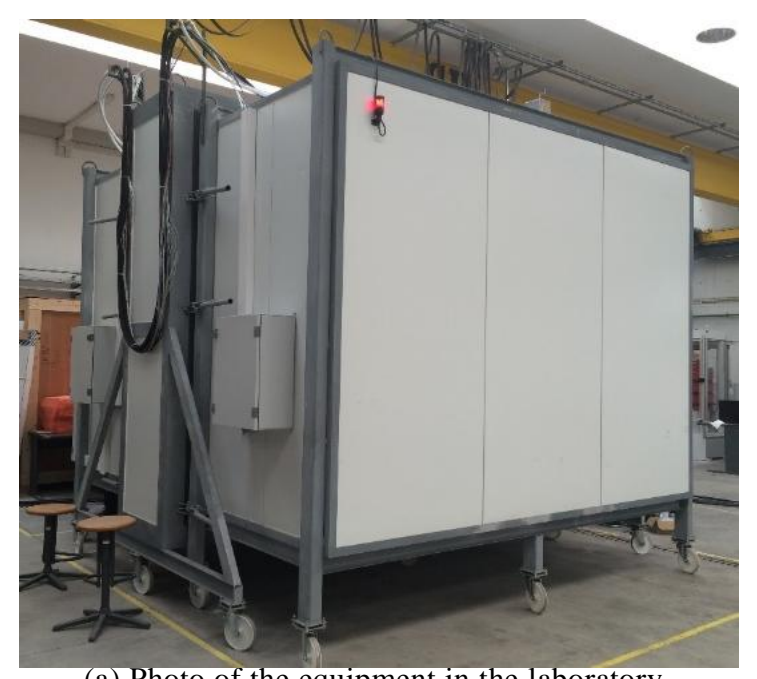

(a) Photo of the equipment in the laboratory

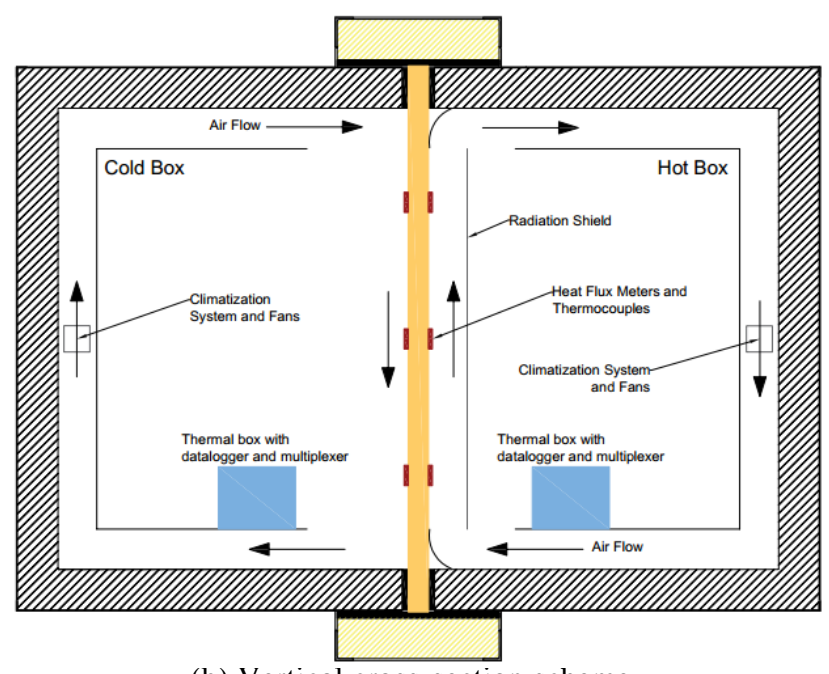

(b) Vertical cross-section scheme

Figure 3. Hot box apparatus.

Figure 4 illustrates the sensors and the data acquisition equipment used in the measurements as well as its precision. In the measurements, 62 thermocouples were used, as well as 12 heat flux sensors (6 on each side of the LSF wall, as illustrated in Figure 5), two air flow meters and two temperature/humidity dataloggers (one for each chamber). These sensors, except the temperature and humidity dataloggers, were connected to two dataloggers (Figure 4e). To reduce the number of channels needed in the dataloggers, two multiplexers were also used to connect thermocouples (Figure 4f). Each pair of datalogger-multiplexer was placed inside the cold and hot chambers, as illustrated in Figure 3(b). To detect eventual thermal stratification of the air inside the chambers, the environment temperatures were recorded by three thermocouples located inside each 
chamber at three different heights - the same location heights of the surface thermocouples and heat flux meters located on the wall specimen (see Figure 3(b) and Figure 5).

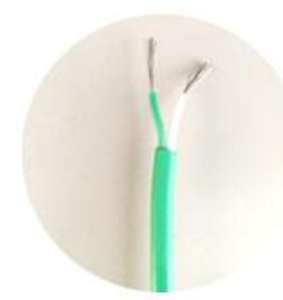

(a) Thermocouple type $\mathrm{K}, T C-A 30 K X$ (precision: $\pm 2.2^{\circ} \mathrm{C}$ )

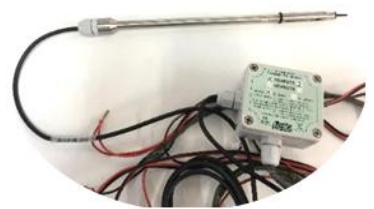

(c) Air flow meter, Delta OHM HD 403 (precision: $0.2 \mathrm{~m} / \mathrm{s}$ )

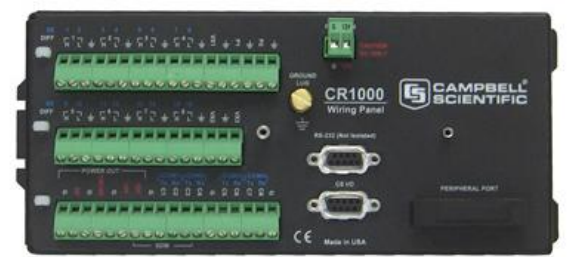

(e) Datalogger, Campbell Scientific CR1000

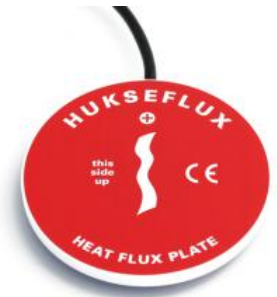

(b) Heat flux meter, Hukseflux HFPO1 (precision: $\pm 5 \%$ )

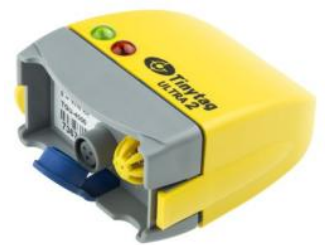

(d) Temperature and humidity datalogger, Tinytag Ultra 2 TGU-4500 (precision: $\pm 3 \%$ )

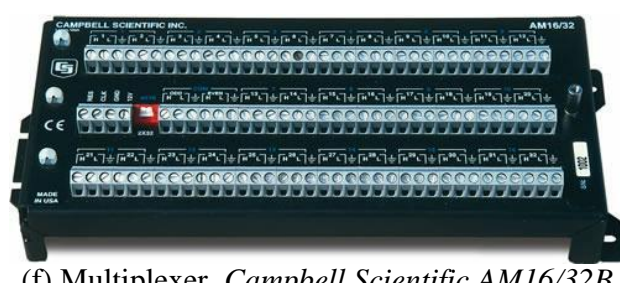

(f) Multiplexer, Campbell Scientific AM16/32B

Figure 4. Sensors and data acquisition equipment used in the experiments.

The three $9.0 \mathrm{~m}^{2}$ LSF walls were installed in the specimen frame, with an area of $9.72 \mathrm{~m}^{2}$, as illustrated in Figure 5. The remaining $10 \mathrm{~cm}$ bottom and top gaps, between the LSF wall and the specimen frame, were filled with XPS material. The thermocouples and the heat flux meters were placed in between and in the vicinity of the vertical steel frames, at different heights and on both wall surfaces (hot and cold surfaces), as illustrated in Figure 5. Notice that some of the sensors located in the vicinity of the vertical steel frames were placed in the middle of the LSF wall module, while others were placed in between them, i.e., in the joint between LSF wall modules (marked as a red line in Figure 5).

The hot chamber can be warmed up to $50{ }^{\circ} \mathrm{C}$ by an electric resistance, while the cold chamber can be cooled down to $0{ }^{\circ} \mathrm{C}$ by a chiller device, allowing to have a maximum temperature difference of $50{ }^{\circ} \mathrm{C}$. To avoid air stratification and simulate wind exterior 
conditions, each chamber has some fans that are capable to induce an air velocity up to $5 \mathrm{~m} / \mathrm{s}$.

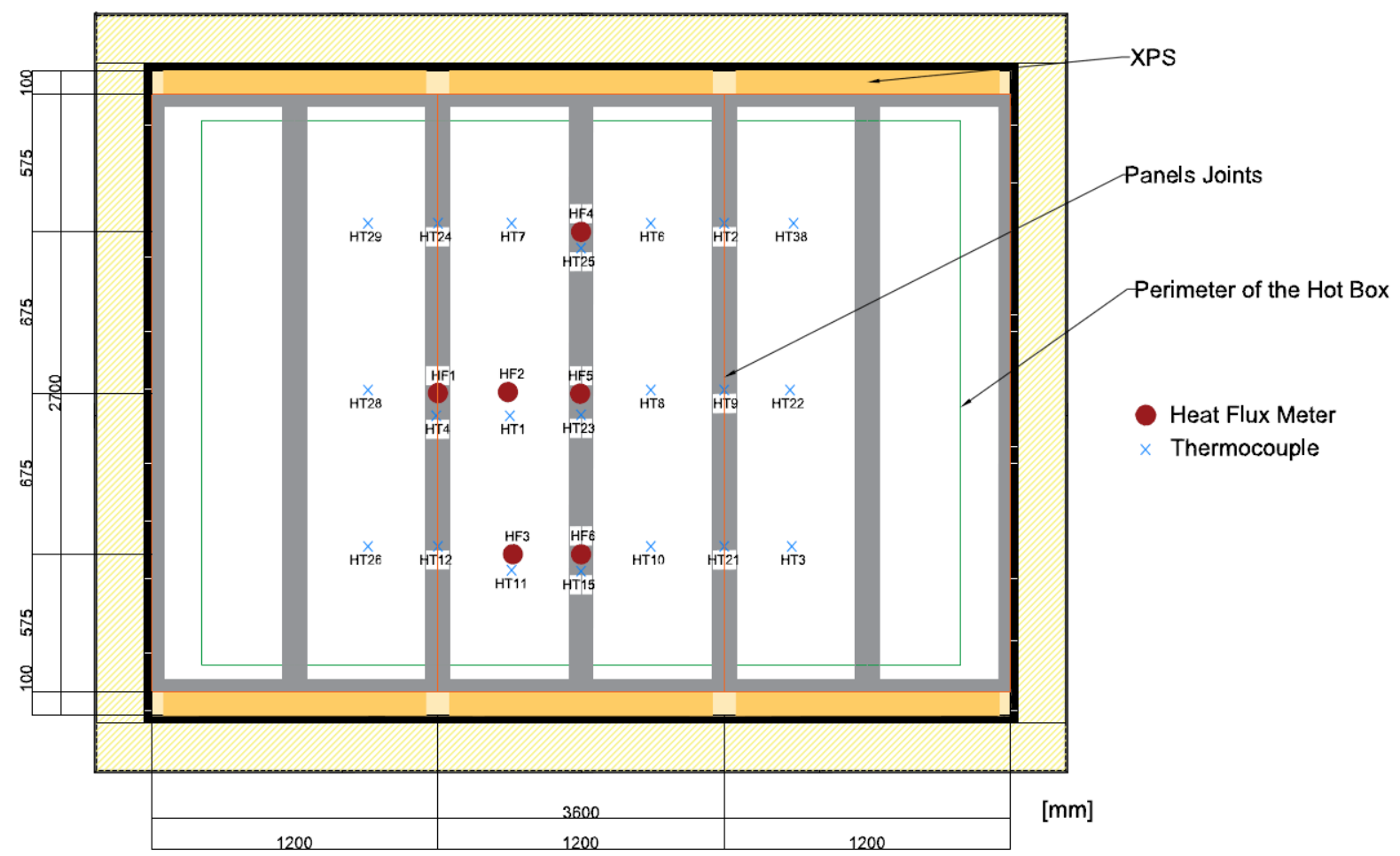

(a) Hot side surface

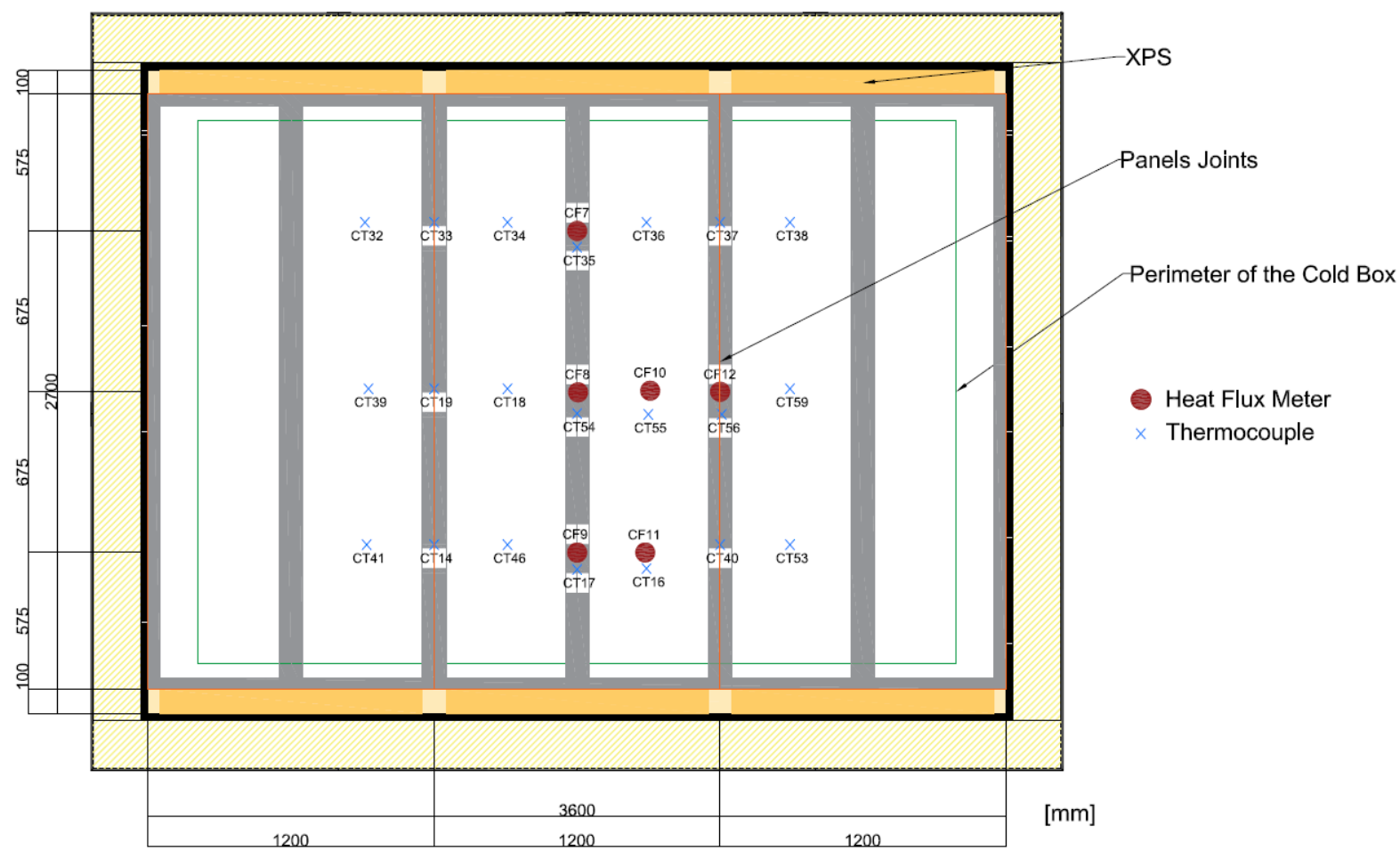

(b) Cold side surface

Figure 5. Location of the sensors on the surfaces of the LSF wall installed in the specimen frame. 


\subsection{Setpoints and test procedures}

The test procedures to measure the thermal performance of the LSF walls followed the prescriptions provided by several international standards, namely ISO 9869 [19], ASTM C 1155-95 [29] and ASTM C 1046-95 [30]. Three experiments were performed for each wall configuration to check for repeatability, and average values will be presented. The tests were performed in steady-state conditions and the temperature setpoints provided for the cold and hot boxes were $15{ }^{\circ} \mathrm{C}$ and $45{ }^{\circ} \mathrm{C}$, respectively. The air velocity setpoint was $0.5 \mathrm{~m} / \mathrm{s}$ for both chambers. The data measured by all the sensors was recorded every five minutes and the computations to obtain the local $U$-value were later performed with average hourly values. The minimum duration of each experiment was 24 hours.

\subsection{Verification of the measurements}

As previously mentioned, to verify the reliability and proper functioning of the experimental setup and sensors, a homogeneous XPS 100 mm-thick wall panel (Figure 2a) was firstly tested, since the thermal conductivity of the XPS material is known (0.036 $\left.\mathrm{W} /\left(\mathrm{m} \cdot{ }^{\circ} \mathrm{C}\right)\right)$. The sensors, the experimental setup and the test procedures were the same as for the LSF walls. Knowing the heat flux and the surface temperature differences, the thermal conductance, $\Lambda$, was computed. Using this value and the thickness of the homogeneous wall, $d=100 \mathrm{~mm}$, the measured thermal conductivity, $\lambda$, was obtained. Table 2 presents the obtained values for the three tests performed, and also the average and standard deviation values. The average absolute difference between the measured thermal conductivity and the value provided by the manufacturer was $c a .+0.002$ $\mathrm{W} /\left(\mathrm{m} \cdot{ }^{\circ} \mathrm{C}\right)$, corresponding to a percentage difference of $+5 \%$, which was found to be acceptable given the sensors precision and other uncertainties.

Table 2. Results of the experimental setup verification for the XPS wall.

\begin{tabular}{ccccc}
\hline & \multicolumn{1}{c}{$\boldsymbol{\Lambda}$} & $\boldsymbol{\lambda}=\Lambda \cdot d$ & \multicolumn{2}{c}{ Error } \\
& {$\left[\mathrm{W} /\left(\mathrm{m} \cdot{ }^{\circ} \mathrm{C}\right)\right]$} & {$\left[\mathrm{W} /\left(\mathrm{m} \cdot{ }^{\circ} \mathrm{C}\right)\right]$} & {$\left[\mathrm{W} /\left(\mathrm{m} \cdot{ }^{\circ} \mathrm{C}\right)\right]$} & {$[\%]$} \\
\hline Test 1 & 0.361 & 0.036 & +0.000 & $+0 \%$ \\
Test 2 & 0.382 & 0.038 & +0.002 & $+6 \%$ \\
Test 3 & 0.372 & 0.037 & +0.001 & $+3 \%$ \\
Average & $\mathbf{0 . 3 7 7}$ & $\mathbf{0 . 0 3 8}$ & $\mathbf{+ 0 . 0 0 2}$ & $\mathbf{+ 5 \%}$ \\
Stand. Dev. & \pm 0.011 & \pm 0.001 & \pm 0.001 & $\pm 3 \%$ \\
\hline$\Lambda$ - Thermal conductance; $\lambda$ - Thermal conductivity; $d$ - Thickness $(0.10 \mathrm{~m})$.
\end{tabular}




\subsection{Measured recorded data}

To illustrate some of the measurements recorded, Figure 6 displays the ambient temperatures, the surface temperatures and the heat flux measured at the LSF wall $\mathrm{n} .3$, i.e., with MW and ETICS. In these plots, it is also marked the convergence zone obtained according with the criterion explained in the next section (3.5). Notice that this convergence criterion ensures a quasi-steady-state regimen, which is quite well visible in these plots. Another interesting feature is the high temperature difference achieved between both wall surfaces $\left(26.8^{\circ} \mathrm{C}\right)$ and between both side environments $\left(28.9^{\circ} \mathrm{C}\right)$, which provides an increased accuracy in the measured thermal transmittance values.

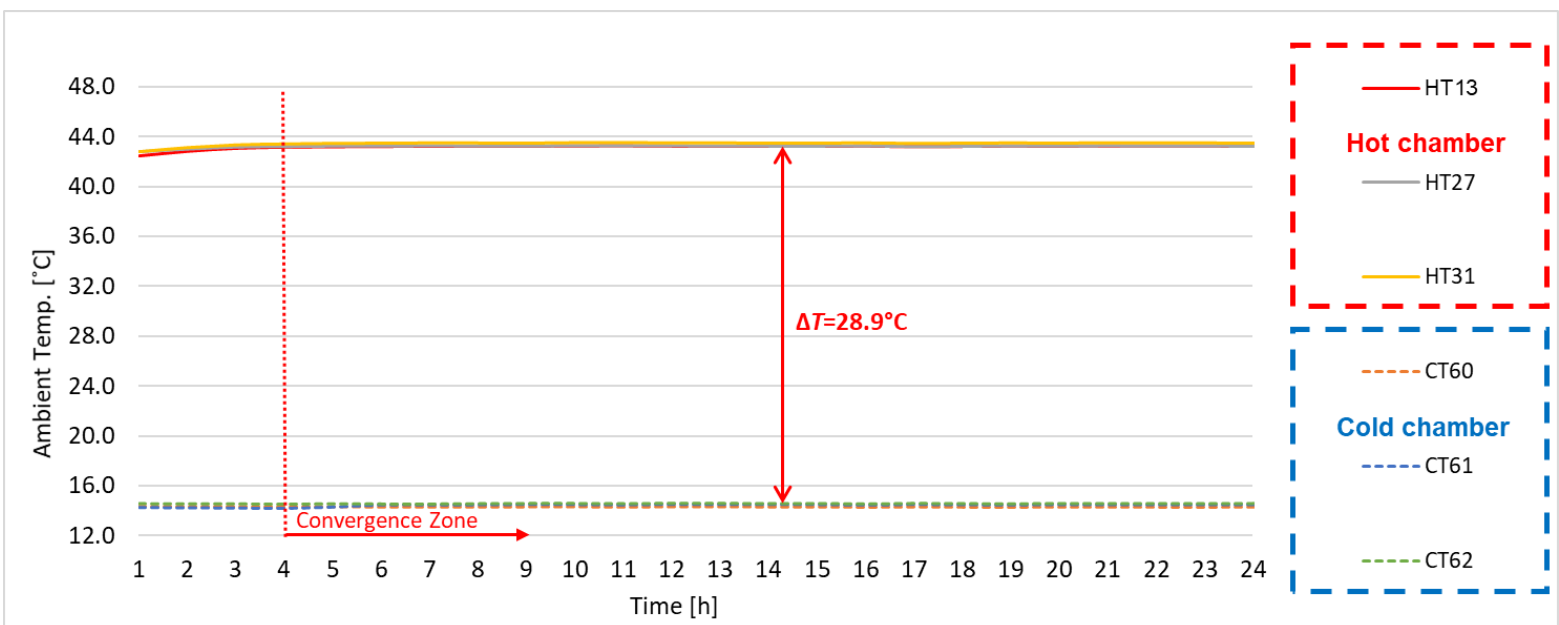

(a) Ambient temperature

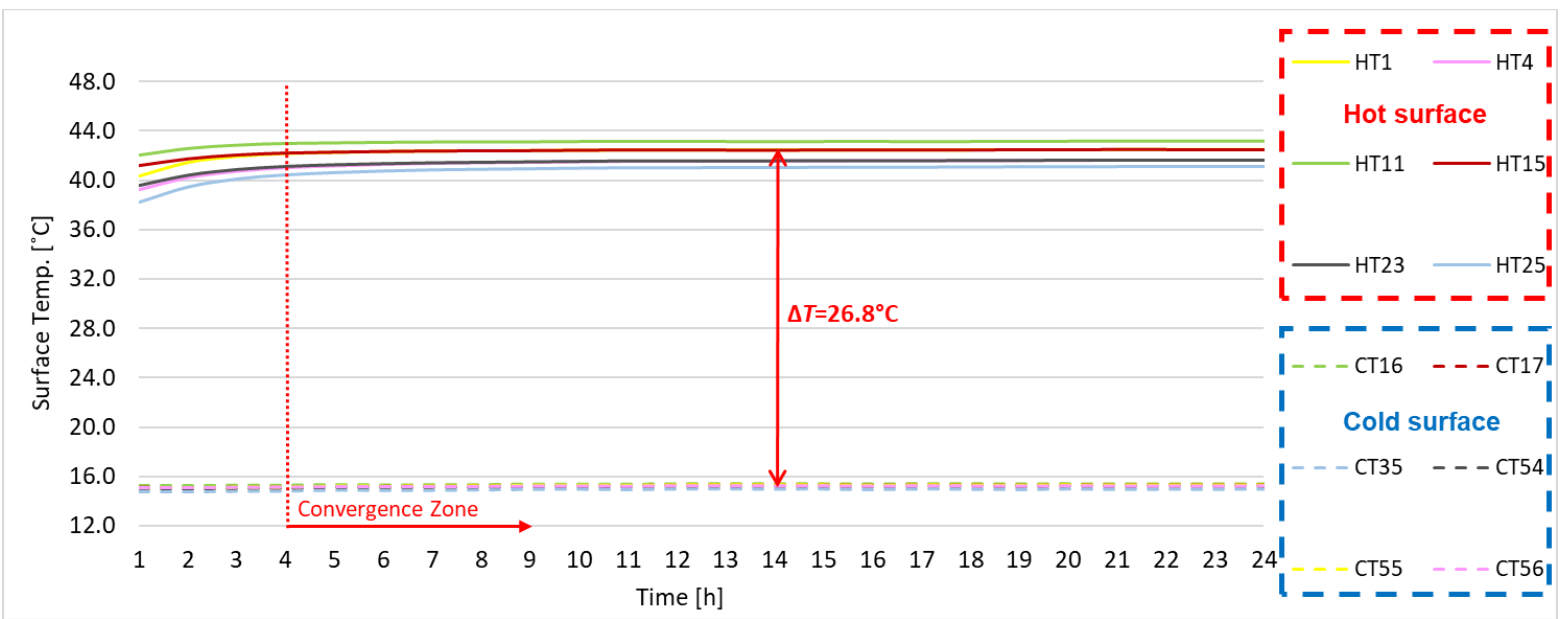

(b) Surface temperature 


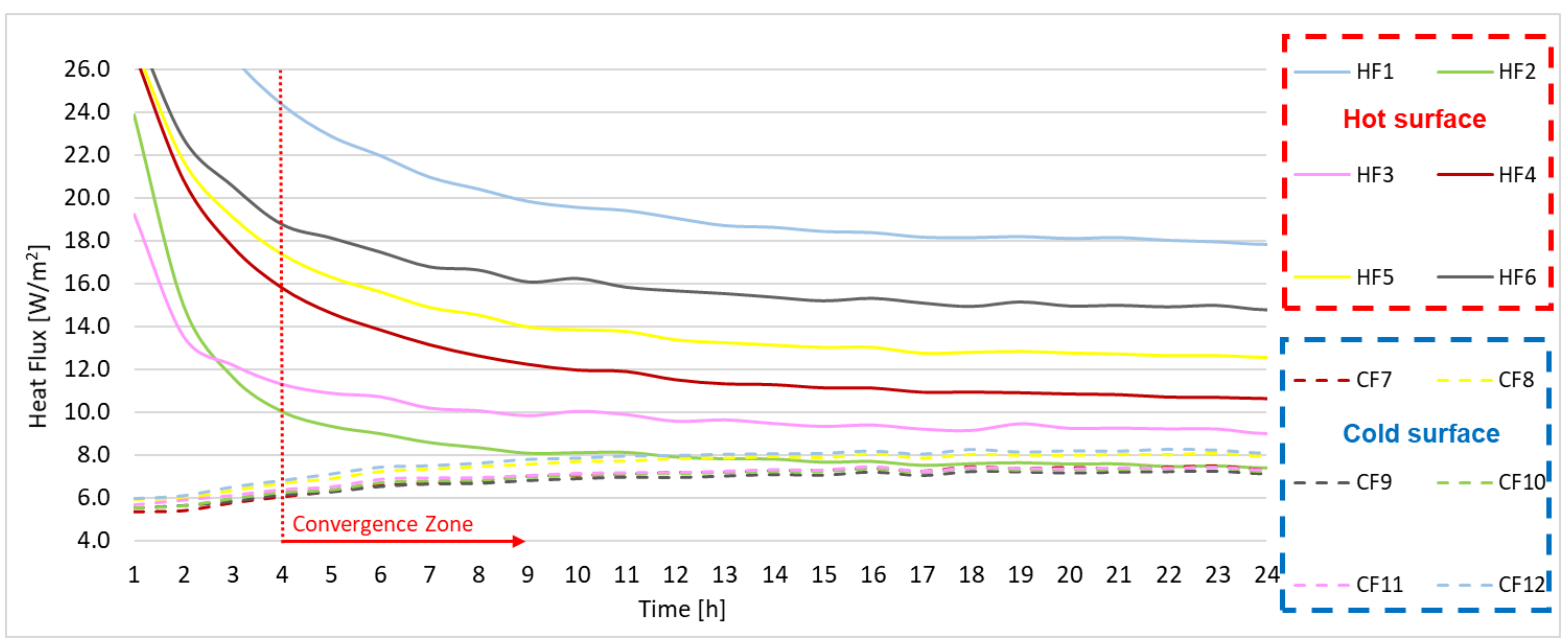

(c) Heat flux

Figure 6. Example of measured data: LSF wall n. 3 (with MW and ETICS).

Due to the air movement imposed inside the chambers $(0.5 \mathrm{~m} / \mathrm{s})$, there is no significant thermal stratification, as the air temperatures recorded by the thermocouples placed at different heights in each chamber are very similar (Figure 6a). Furthermore, the temperature distribution recorded on the cold surface of the wall is more uniform than on the hot surface (Figure 6b). This could be due to the ETICS layer applied on the cold side of the wall, reducing the influence of the steel frame thermal bridges. The effect of the continuous thermal insulation applied on the cold wall surface is even more visible on the heat flux values recorded on that surface. They are much more similar than the ones recorded on the hot surface (Figure 6c). The highest heat flux values were recorded by the HF1 sensor, which was placed in the vicinity of the steel frame on the joint between panels (see Figure 5a). The second highest heat flux values were recorded also in the vicinity of the steel frame but in the middle of the panel (HF4, HF5 and HF6). As expected, the lowest heat flux values were recorded by the HF2 and HF3 sensors, which were placed between the steel frames, where there is no influence of the thermal bridges (Figure 6c). 


\subsection{Thermal transmittance computation}

Because the local $U$-values were obtained for steady-state conditions using the HFM method, the computations were performed accordingly with the procedures presented in several standards for in situ measurements. The convergence criterion defined in standard ASTM C 1155-95 [29] (section 6.5.1.1) is used to select the recorded data that will be used in the thermal transmittance computation. According with this criterion, there is convergence when the difference between the thermal resistance computed for a time interval (e.g. 1 hour) and the previous one is lower than $10 \%$.

First, the local $U$-values are computed using the time average temperature differences and heat fluxes for representative parts of the heterogeneous wall (e.g. between and near the steel profiles). Afterwards, the overall value for the wall is weighted in accordance with the area of influence of each sensor location. This influence area was determined using the ASHRAE zone method [28].

\subsection{Measured thermal transmittance values}

Table 3 presents the local and the overall thermal transmittance values obtained for the LSF walls using the experimental results. Notice that three representative LSF wall sections were used to compute local $U$-values, namely: section 0 , representing the area between the vertical steel studs; section 1, representative of the area nearby the vertical steel studs in the middle of the LSF module with only one wood slat; and section 2 for the area nearby the steel studs in the joints between LSF modules with two wood slats. 
Table 3. $U$-values obtained for the LSF walls based on experimental data.

Wold Chamber
Wall typology

In the LSF wall n.1, the wood slats allowed to reduce the thermal bridge effect originated by the steel studs. The thermal transmittance reduction was of $-26 \%$ and $-10 \%$ for 1 and 2 wood slats, respectively. The overall weighted $U$-value for the LSF wall n.1 was $1.266 \mathrm{~W} /\left(\mathrm{m}^{2} \cdot{ }^{\circ} \mathrm{C}\right)$. Filling the air-cavity with $50 \mathrm{~mm}$ of mineral wool (LSF wall n. 2, Table 3) allowed to significantly reduce the overall thermal transmittance of the wall $(-58 \%)$. This reduction was higher between the steel studs (-64\%) and lower near the steel studs ($39 \%$ and $-27 \%$ for 1 and 2 wood bars, respectively). The overall $U$-value for the LSF wall n.2 decreased by $58 \%$, to $0.534 \mathrm{~W} /\left(\mathrm{m}^{2} \cdot{ }^{\circ} \mathrm{C}\right)$. Given the thermal insulation continuity of the ETICS (LSF wall n. 3, Table 3), the thermal bridging effect of the steel studs was reduced, resulting in $U$-values closer to each other between and near the steel profiles. The overall $U$-value for the LSF wall n. 3 decreased $76 \%$ and $43 \%$ in relation to the LSF wall n. 1 and LSF wall n.2, respectively. The obtained overall $U$-value of the LSF wall n.3 was 0.302 $\mathrm{W} /\left(\mathrm{m}^{2} \cdot{ }^{\circ} \mathrm{C}\right)$ 


\section{Numerical simulations}

\subsection{D FEM simulations}

The FEM software ANSYS CFX (release 18.2) was used to perform the 3D FEM numerical simulations of the LSF walls previously tested. The corresponding model is explained next.

\subsubsection{Numerical domain}

In the $3 \mathrm{D}$ simulations, only a representative part of the LSF wall, $1.20 \mathrm{~W} \times 1.25 \mathrm{H}[\mathrm{m}]$, was modelled as illustrated in Figure 7.

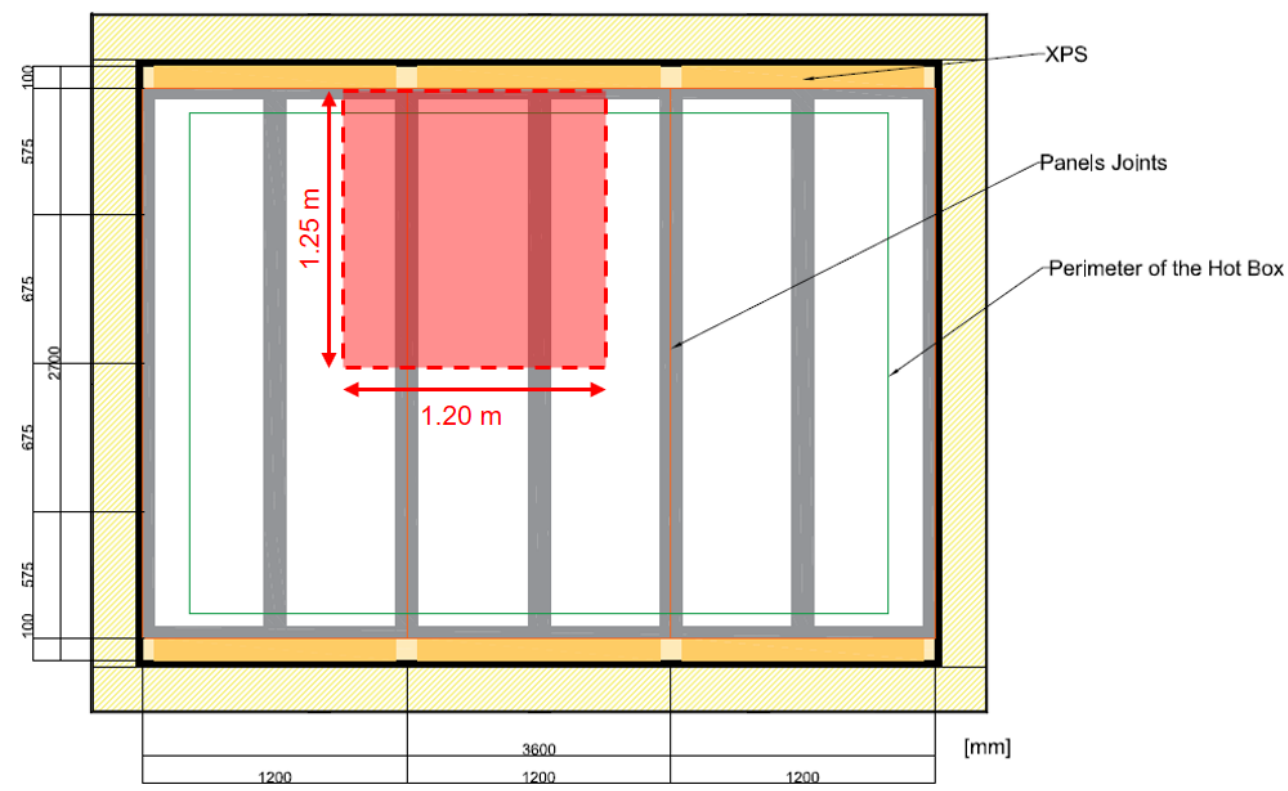

Figure 7. Region of the LSF wall modelled in 3D FEM simulations: hot surface view.

\subsubsection{Boundary conditions}

The boundary conditions for the hot and cold sides of the wall (ambient temperatures, $T_{\mathrm{i}}$ and $T_{\mathrm{e}}$, and surface thermal resistances, $R_{\mathrm{si}}$ and $\left.R_{\mathrm{se}}\right)$ were taken from the experimental tests. Figure 8 displays the average values measured and modelled for the LSF wall $\mathrm{n} .1$ (without thermal insulation). Moreover, several adiabatic boundaries were defined, including at the perimeter of the LSF wall region modelled. Furthermore, two more adiabatic regions $(0.11 \mathrm{~m}$ height $)$ were defined at the top of the internal and external wall 
surfaces, being this related to the perimeter of the hot and cold boxes as illustrated in Figure 5(a) and (b), respectively.

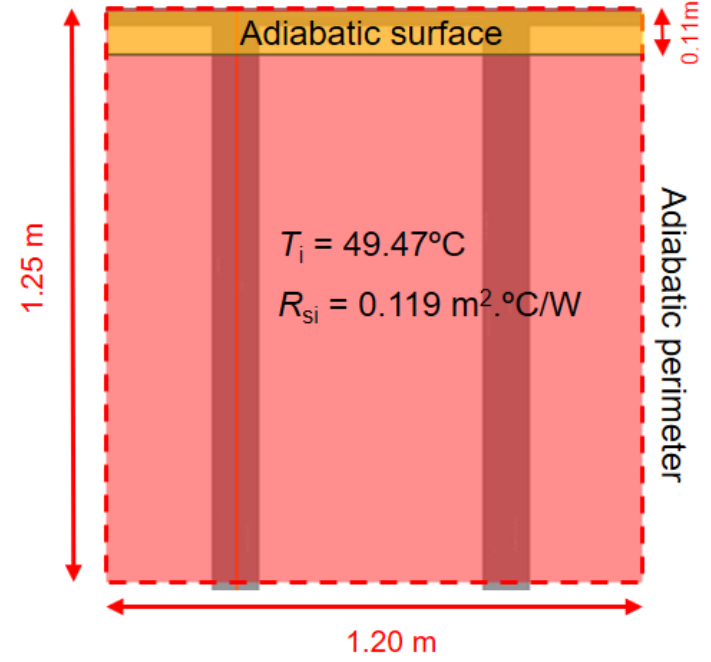

(a) Hot side (interior surface)

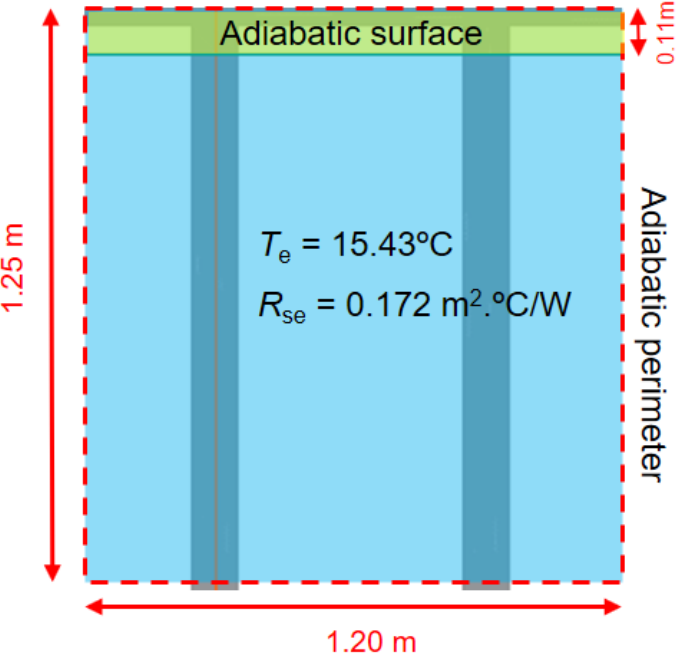

(b) Cold side (exterior surface)

Figure 8. Boundary conditions used in 3D FEM simulations for the LSF wall n. 1: $T_{\mathrm{i}}$ - Interior environment temperature; $R_{\mathrm{Si}}$ - Internal surface thermal resistance; $T_{\mathrm{e}}$ - Exterior environment temperature; $R_{\mathrm{se}}$ - External surface thermal resistance.

\subsubsection{Modelling air spaces and solid-equivalent thermal conductivity}

The ISO 6946 [24] presents a table of values with the equivalent thermal resistance for unventilated air gaps. A thermal resistance of $0.18 \mathrm{~m}^{2} \cdot \mathrm{K} / \mathrm{W}$ is prescribed for an air layer with a thickness between 25 and $300 \mathrm{~mm}$, assuming a horizontal heat flow. Taking into account the air layers thicknesses of $96 \mathrm{~mm}$ and $146 \mathrm{~mm}$, a solid-equivalent thermal conductivity of 0.811 and $0.533 \mathrm{~W} /\left(\mathrm{m} \cdot{ }^{\circ} \mathrm{C}\right)$, respectively, was obtained and assumed for modelling.

\subsection{D FEM simulations}

The FEM software THERM (release 7.6.01) was used to perform the 2D FEM numerical simulations of the LSF walls previously tested, as described in the next sections. 


\subsubsection{Numerical domain}

Given the two-dimensionality assumption, only a horizontal cross-section of the characteristic part of the tested LSF wall (Figure 7), with 1.20 m length, will be modelled. Figure 9 displays the geometry of the 2D FEM models for each one of the three LSF walls.

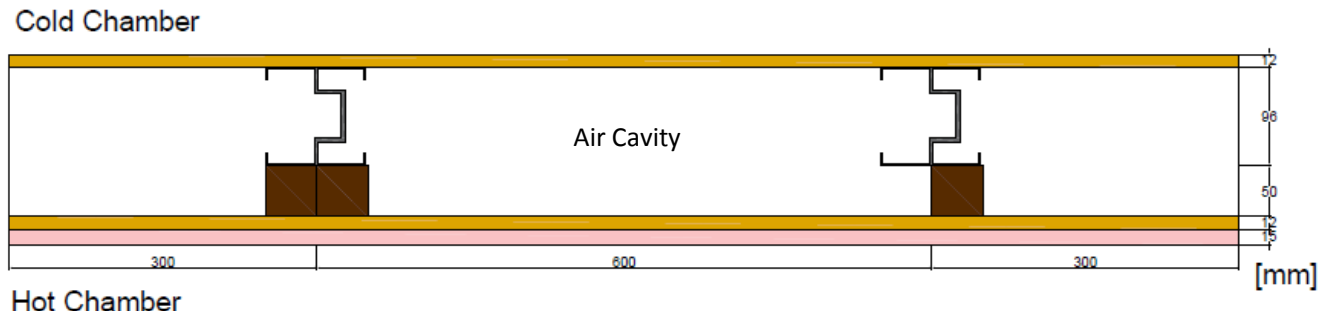

(a) LSF wall n. 1 - Without thermal insulation

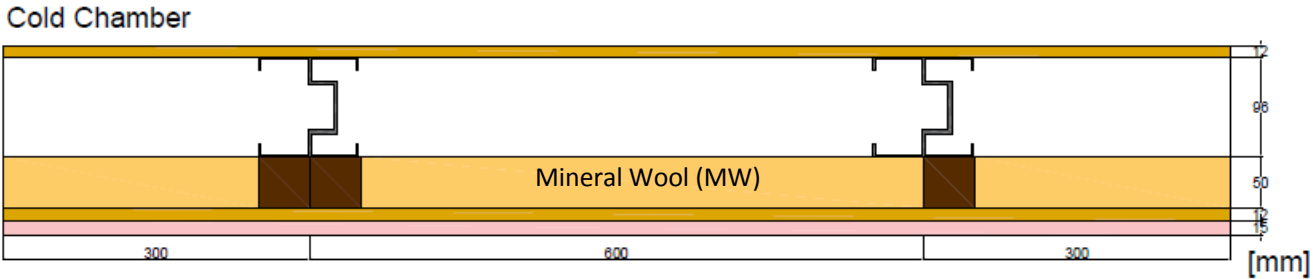

$\begin{array}{ll}\text { Hot Chamber } & \text { (b) LSF wall n. } 2 \text { - With MW in the air-cavity }\end{array}$

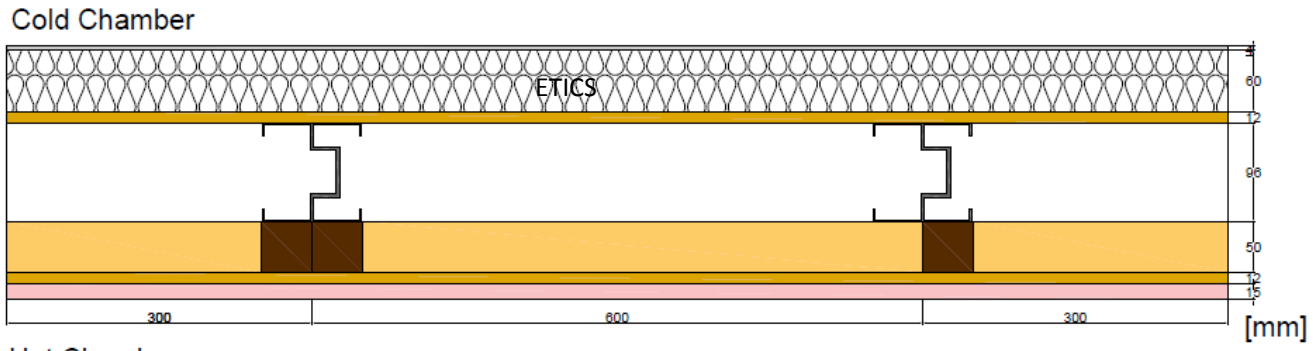

Hot Chamber

(c) LSF wall n. 3 - With MW in the air-cavity and ETICS

Figure 9. LSF wall cross-sections modelled in the 2D FEM simulations.

\subsubsection{Boundary conditions}

The boundary conditions for the hot and cold sides of the wall (ambient temperatures, $T_{\mathrm{i}}$ and $T_{\mathrm{e}}$, and surface thermal resistances, $R_{\mathrm{si}}$ and $\left.R_{\mathrm{se}}\right)$ were also taken from the experimental tests. Besides these interior (hot) and exterior (cold) boundary conditions, two adiabatic boundary surfaces were defined at the left and right sections of the modelled region (Figure 9). 


\subsubsection{Modelling air spaces and solid-equivalent thermal conductivity}

The air-gaps in the $2 \mathrm{D}$ simulations were modelled using the same strategy as in $3 \mathrm{D}$ simulations, i.e., using a solid-equivalent thermal conductivity (see section 4.1.3).

\subsection{Verification of FEM models accuracy}

Besides the comparison between the experimental results and the results obtained by $3 \mathrm{D}$ and 2D FEM simulations, and by the ISO 6946 analytical approach (see section 6.1), the authors also performed other verifications to ensure the accuracy of the FEM models. Firstly, the test-cases provided by standard ISO 10211 [31] were used. Then, some simplified wall models with homogeneous layers, for which the analytical solution is known, were taken as reference. Finally, the LSF wall surface temperature distribution predicted by the 3D FEM simulations was compared with infrared (IR) thermographic images captured after the experimental tests.

\subsubsection{Standard ISO 10211}

Annex 2 of the standard ISO 10211 [31] provides four reference test cases to evaluate the accuracy of numerical algorithms to compute surface temperatures and heat flows. To verify the reliability of the FEM models used in this work, the authors modelled all these test cases. Figure 10 displays the temperature distribution predicted by THERM algorithm for the first two 2D reference test cases. The average temperature difference between the standard values and the values predicted by THERM is only $0.007^{\circ} \mathrm{C}$ for the $1^{\text {st }}$ test case, and exactly the same for the $2^{\text {nd }}$ test case values, showing an excellent accuracy of this algorithm. Analogous procedures were implemented for the 3D test cases using the ANSYS algorithm and similar conclusions were obtained (not illustrated). 


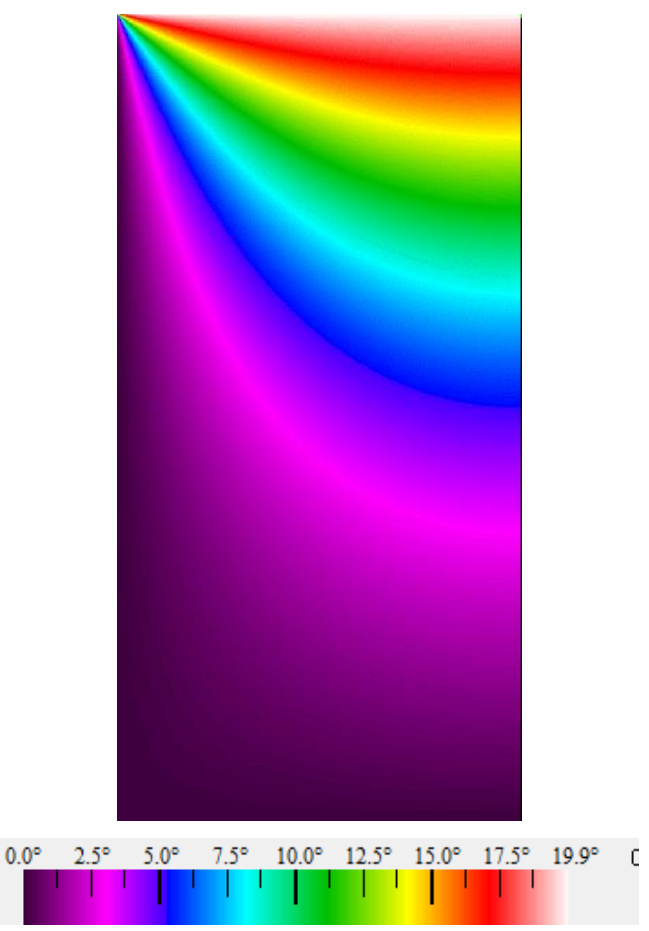

(a) Reference test case 1

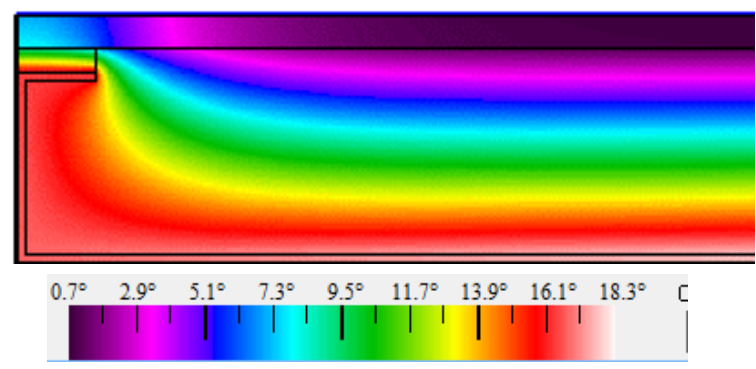

(b) Reference test case 2

Figure 10. Temperature distribution predicted by THERM for the 2D test cases of ISO 10211 [31].

\subsubsection{Simplified models}

Another verification performed to check the accuracy of the FEM models was to compare the numerical results obtained for simplified wall models with homogeneous layers, for which the analytical solution is known. Three wall models were defined, similar to the ones illustrated in Figure 9, but without the steel and wood frames. The obtained results are displayed in Table 4. As expected the obtained thermal transmittance values are equal, thus ensuring the reliability of the FEM models.

Table 4. $U$-values obtained for the simplified wall models with homogeneous layers.

\begin{tabular}{|c|c|c|c|}
\hline \multirow[b]{2}{*}{ Wall typology } & \multicolumn{3}{|c|}{ Thermal transmittance, $\boldsymbol{U}\left[\mathrm{W} /\left(\mathrm{m}^{2} \cdot{ }^{\circ} \mathrm{C}\right)\right]$} \\
\hline & 3D FEM & 2D FEM & Analytical \\
\hline LSF wall n. 1 - without thermal insulation & 1.399 & 1.399 & 1.399 \\
\hline LSF wall n. 2 - with MW in the air-cavity & 0.476 & 0.476 & 0.476 \\
\hline LSF wall n. 3 - with MW in the air-cavity and ETICS & 0.274 & 0.274 & 0.274 \\
\hline
\end{tabular}




\subsubsection{IR thermography images}

IR thermography images of the three LSF walls were captured after the experimental tests and the surface temperature distribution was compared with the predictions of the 3D FEM models as illustrated in Figure 11. In both approaches, the location of the vertical steel studs is well visible, except in the LSF wall n.3 with ETICS, confirming its high efficacy to mitigate steel frame thermal bridging. The major difference between the surface temperature distributions is related with the thermal stratification, which is well visible in the IR images, but not visible in ANSYS predictions since the air was modelled as a solid-equivalent material. Another difference is related with the ETICS fixing bolts, which are not visible in the FEM predictions since they were neglected. Nevertheless, the results are satisfactory, showing a good agreement between the IR captured images and the predicted surface temperatures distribution.

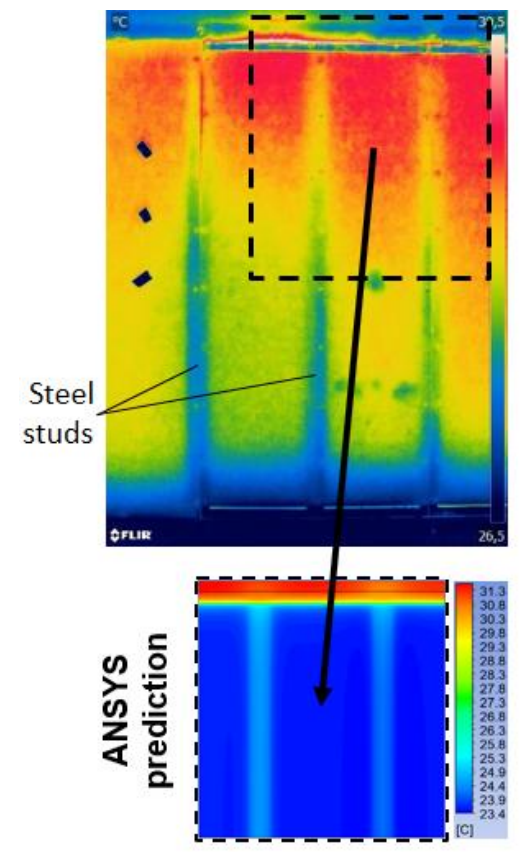

(a) LSF wall n. 1

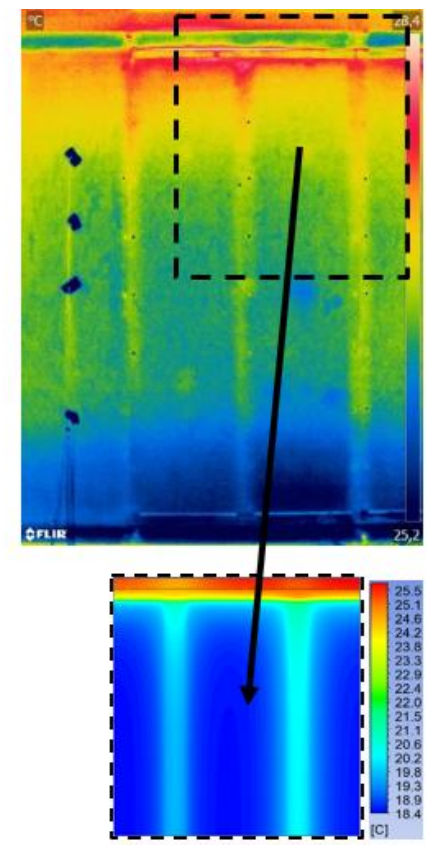

(b) LSF wall n. 2

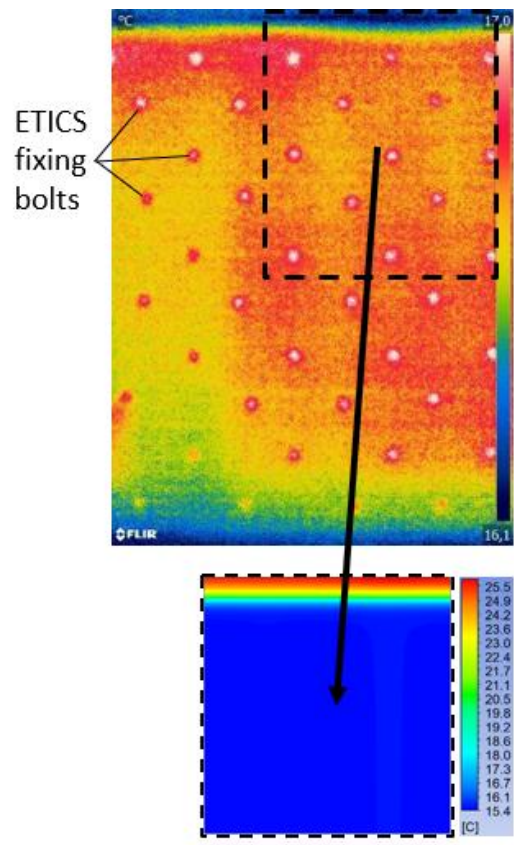

(c) LSF wall n. 3

Figure 11. Surface temperature distribution (cold side): IR images and 3D FEM predictions. 


\section{Analytical approach}

The $U$-values of the three LSF walls were also evaluated using the analytical approach (combined method) for non-homogeneous walls defined in ISO 6946 [24]. This procedure is possible as the steel frame of the walls never bridges the thermal insulation. In this methodology, the total thermal resistance of the wall is given by the arithmetic mean of the upper and lower limits of the thermal resistance. To compute these limit resistances, the cross-section of the wall should be divided into sections and layers, perpendicular and parallel to the wall surfaces, respectively. Figure 12 displays the nine sections and the different layers defined for the evaluated LSF walls cross-sections. Two simplifications were introduced to reduce the number of sections and layers: $(i)$ the flanges of the steel studs were neglected; and (ii) the web male/female deformations were ignored. The upper limit of the total thermal resistance is computed assuming one-dimensional heat flow perpendicular to the surfaces of the wall, while the lower limit is calculated assuming isothermal surfaces within all planes parallel to the surfaces of the wall. According to ISO 6946 [24], the maximum relative error when using this method is given by the difference between the upper and lower limit, divided by two times the total thermal resistance of the wall. 


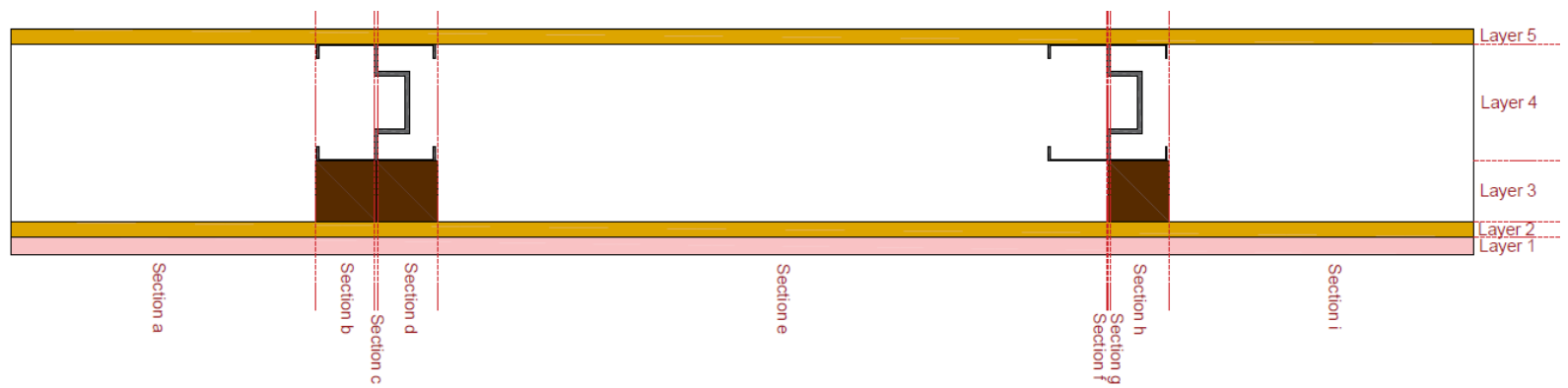

(a) LSF wall n. 1 - Without thermal insulation

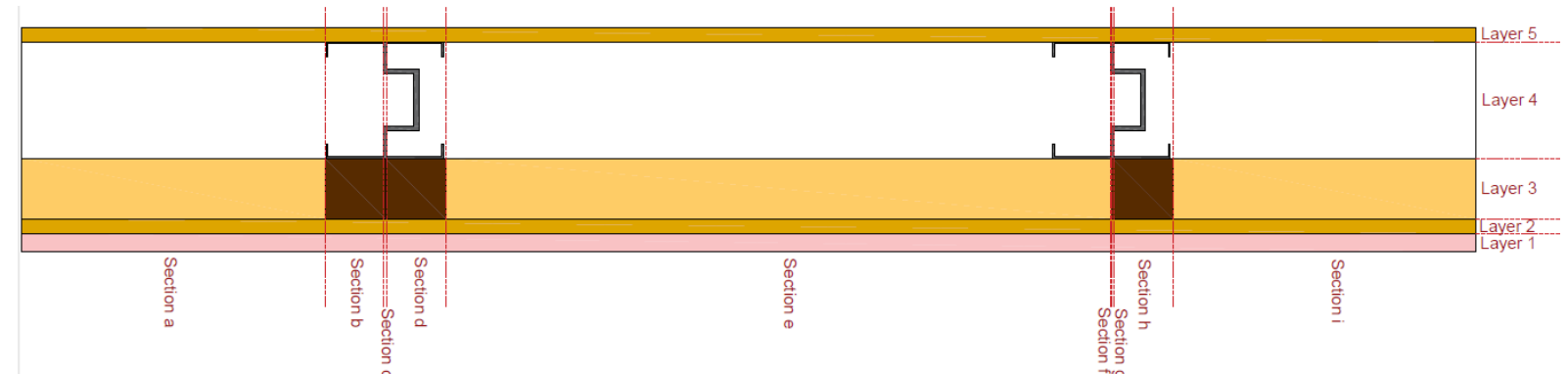

(b) LSF wall n. 2 - With MW in the air-cavity

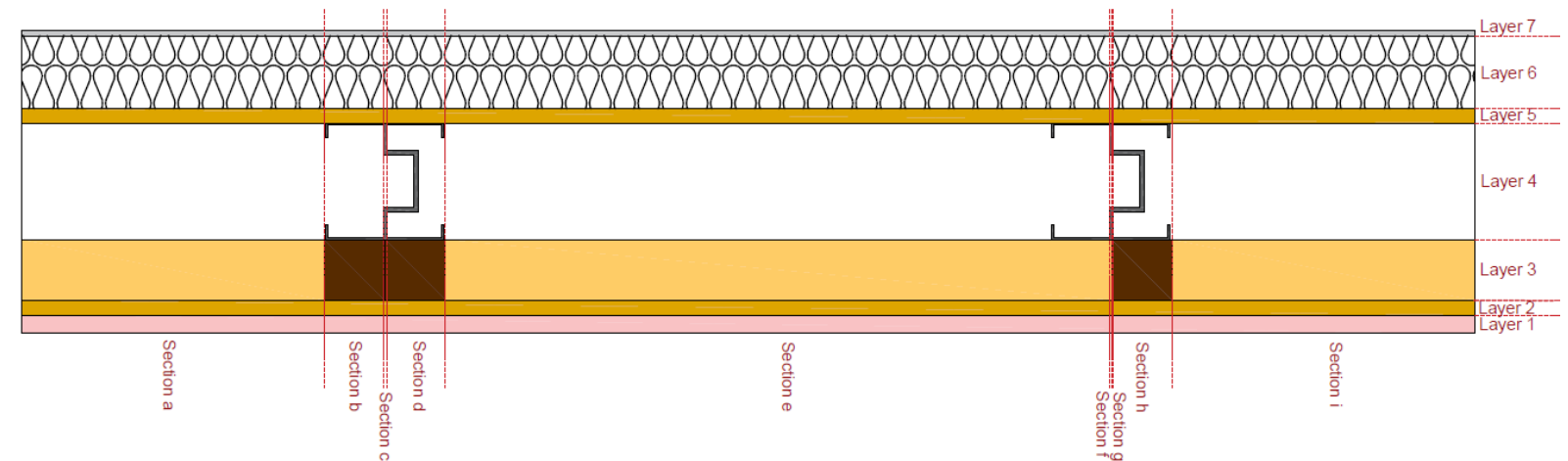

(c) LSF wall n. 3 - With MW in the air-cavity and ETICS

Figure 12. Sections and layers defined for the three LSF walls as prescribed in ISO 6946 [24].

\subsection{Verification of analytical approach accuracy}

Table 5 presents a comparison between the $U$-values obtained using the 2D FEM approach and the ISO 6946 [24] analytical approach for inhomogeneous layers, as well as the differences between both approaches, and the maximum relative errors predicted by ISO 6946 [24] for the analytical combined method. Both approaches provided very similar values, the maximum difference of $+2.6 \%$ was verified for the LSF wall n. 1. As expected, when there is a continuous homogenous thermal insulation layer, the analytical approach gives better results, and the $U$-values obtained for the LSF wall n. 3 are similar for both approaches. Also, as predicted by ISO 6946 [24], all the obtained differences are lower than the maximum estimated error expected for this analytical methodology. 
Table 5. $U$-values obtained for the tested LSF walls: 2D FEM and analytical approaches.

\begin{tabular}{lcccccc}
\hline & \multicolumn{2}{c}{ LSF wall n. 1 } & \multicolumn{2}{c}{ LSF wall n. 2 } & \multicolumn{2}{c}{ LSF wall n. 3 } \\
& 2D FEM & ISO 6946 & 2D FEM & ISO 6946 & 2D FEM & ISO 6946 \\
\hline $\boldsymbol{U}$-value $\left[\mathrm{W} /\left(\mathrm{m}^{2} \cdot{ }^{\circ} \mathrm{C}\right)\right]$ & 1.399 & 1.396 & 0.581 & 0.596 & 0.306 & 0.306 \\
Absolute difference & --- & -0.003 & --- & +0.015 & --- & 0.000 \\
Percentage difference & --- & $-0.2 \%$ & --- & $+2.6 \%$ & --- & $0.0 \%$ \\
ISO 6946 max. error & --- & $\pm 3.3 \%$ & --- & $\pm 6.6 \%$ & --- & $\pm 4.4 \%$ \\
\hline
\end{tabular}




\section{Results and discussion}

\subsection{Thermal transmittance values}

Table 6 presents the $U$-values provided by the experimental measurements, and obtained from the 3D and 2D FEM simulations and the ISO 6946 [24] analytical approach. The differences between measurements and numerical predictions are quite small ([0.004; $0.142] \mathrm{W} /\left(\mathrm{m}^{2} \cdot{ }^{\circ} \mathrm{C}\right)$ or $\left.[1.3 ; 14.0] \%\right)$, being the measured $U$-values lower than the ones obtained from numerical simulations and analytical predictions. These differences could be caused by several features: $(i)$ sensors imprecision, (ii) inaccuracy in the sensors location, (iii) workmanship imperfections, (iv) joints between panels that were not modelled, (v) neglected convection effects inside the air-cavity, etc. The differences, in absolute values, are greater for the LSF wall n.1 (without thermal insulation). For this simple configuration of LSF walls (with only vertical steel studs in the metering area), the accuracy of the 2D FEM models is very good, similar to the 3D models and significantly better for the LSF walls n. 2 and 3, with a difference of only $+8.8 \%$ and $+1.3 \%$, respectively. As previously mentioned, the precision of the analytical method is excellent, being similar to the 2D FEM approach.

Table 6. Comparison between the $U$-values obtained for the three LSF walls considering the experimental results as reference.

\begin{tabular}{lcccc}
\hline & Experimental & 3D FEM & 2D FEM & ISO 6946 \\
\hline $\mathbf{L S F}$ wall n. 1 - without thermal insulation & & & & \\
$\boldsymbol{U}$-value $\left[\mathrm{W} /\left(\mathrm{m}^{2} \cdot{ }^{\circ} \mathrm{C}\right)\right]$ & 1.266 & 1.408 & 1.399 & 1.396 \\
$\begin{array}{l}\text { Absolute difference } \\
\text { Percentage difference }\end{array}$ & --- & +0.142 & +0.133 & +0.130 \\
\hline $\mathbf{L S F}$ wall n. 2 - with MW in the air-cavity & & $+11.2 \%$ & $+10.5 \%$ & $+10.3 \%$ \\
$\boldsymbol{U}$-value $\left[\mathrm{W} /\left(\mathrm{m}^{2} \cdot{ }^{\circ} \mathrm{C}\right)\right]$ & 0.534 & 0.609 & 0.581 & 0.596 \\
Absolute difference & --- & +0.075 & +0.047 & +0.062 \\
Percentage difference & --- & $+14.0 \%$ & $+8.8 \%$ & $+11.6 \%$ \\
\hline $\mathbf{L S F}$ wall n. 3 - with MW and ETICS & & & & \\
$\boldsymbol{U}$-value $\left[\mathrm{W} /\left(\mathrm{m}^{2} \cdot{ }^{\circ} \mathrm{C}\right)\right]$ & 0.302 & 0.322 & 0.306 & 0.306 \\
Absolute difference & --- & +0.020 & +0.004 & +0.004 \\
Percentage difference & --- & $+6.6 \%$ & $+1.3 \%$ & $+1.3 \%$ \\
\hline
\end{tabular}


In order to compare the previous values with the thermal performance of a masonry ceramic brick wall, the $U$-value of a masonry ceramic brick wall was also computed analytically, i.e., assuming homogeneous layers. For this comparison it was adopted a single brick wall with the same total thickness of the LSF wall $(249 \mathrm{~mm})$. The ceramic brick thickness is $150 \mathrm{~mm}$, which is coated with mortar in both faces. For thermal insulation of this masonry wall, it was assumed the same ETICS materials and thicknesses as in the LSF wall n. 3. The obtained $U$-value was $0.478 \mathrm{~W} /\left(\mathrm{m}^{2} \cdot{ }^{\circ} \mathrm{C}\right)$, which is $55 \%$ higher than the average $U$-value obtained for the LSF wall n.3, confirming the good thermal performance of the LSF system.

\subsection{Surface temperatures}

Figure 13 displays the temperature distributions predicted by the 3D FEM simulations for the hot and cold surfaces. As expected, it is well visible the presence of the vertical steel studs on both hot and cold surfaces. There is one exception, i.e., the cold surface of the LSF wall n. 3 (with ETICS), where it is not possible to distinguish the presence of the two steel profiles, as previously mentioned in the comments of Figure 11.
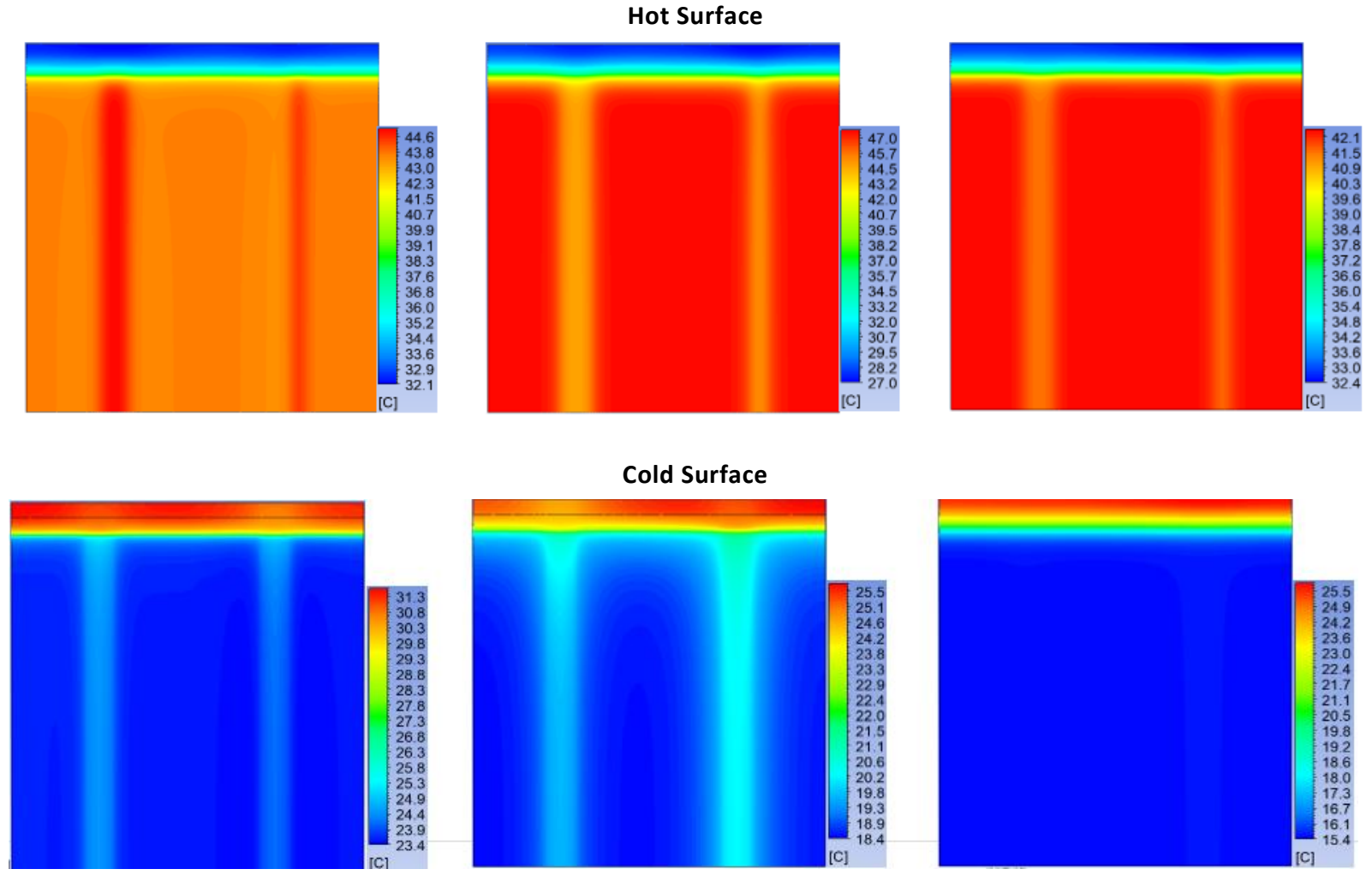

(a) LSF wall n. 1

(b) LSF wall n. 2

(c) LSF wall n. 3

Figure 13. Hot and cold surfaces temperature distribution predicted by 3D FEM models. 
Table 7 presents the average surface temperatures measured during the experiments and predicted by 3D (ANSYS) and 2D (THERM) FEM models. The differences between the predictions and the measurements are minimal $\left([0.14 ; 2.11]{ }^{\circ} \mathrm{C}\right.$ or $\left.[0.3 ; 9.8] \%\right)$. These differences are higher on the cold side surface and for the LSF wall $\mathrm{n}$. 1. The results also show that the accuracy of 2D FEM simulations is better than the one provided by ANSYS 3D models for most of the LSF walls and surfaces. This is due to the fact of the evaluated LSF walls have a straightforward configuration, i.e., only vertical steel profiles in the metering area.

Table 7. Hot and cold average surface temperatures: experimental measurements and numerical predictions for the three tested LSF walls.

\begin{tabular}{rcccccccccc}
\hline & \multicolumn{3}{c}{ LSF wall n. 1 } & \multicolumn{3}{c}{ LSF wall n. 2 } & \multicolumn{3}{c}{ LSF wall n. 3 } \\
& Exp. & ANSYS THERM & Exp. & ANSYS THERM & Exp. & ANSYS THERM \\
\hline $\boldsymbol{T}_{\text {SHot }}\left[{ }^{\circ} \mathrm{C}\right]$ & 45.02 & 43.78 & 43.80 & 46.27 & 46.55 & 46.70 & 42.06 & 42.22 & 42.20 \\
Absolute difference $\left[{ }^{\circ} \mathrm{C}\right]$ & --- & -1.24 & -1.22 & --- & +0.28 & +0.43 & --- & +0.16 & +0.14 \\
Percentage difference & --- & $-2.8 \%$ & $-2.7 \%$ & --- & $+0.6 \%$ & $+0.9 \%$ & -- & $+0.4 \%$ & $+0.3 \%$ \\
$\boldsymbol{T}_{\text {SCold }}\left[{ }^{\circ} \mathrm{C}\right]$ & 21.55 & 23.66 & 23.60 & 17.46 & 18.02 & 17.80 & 15.22 & 15.47 & 15.40 \\
Absolute difference $\left[{ }^{\circ} \mathrm{C}\right]$ & --- & +2.11 & +2.05 & --- & +0.56 & +0.34 & --- & +0.25 & +0.18 \\
Percentage difference & --- & $+9.8 \%$ & $+9.5 \%$ & --- & $+3.2 \%$ & $+1.9 \%$ & --- & $+1.6 \%$ & $+1.2 \%$ \\
\hline
\end{tabular}

\subsection{Cross-section temperatures}

Figure 14 illustrates the temperature distributions predicted by the numerical simulations along a horizontal cross-section of the three LSF walls. As expected, given the plainness of the LSF walls with only vertical steel studs, a very good agreement is observed between the two numerical approaches. Moreover, these plots allow to confirm the steel studs thermal bridge mitigation effect provided by the wood bars when there is no thermal insulation (LSF wall n. 1) and by the ETICS (LSF wall n. 3). 

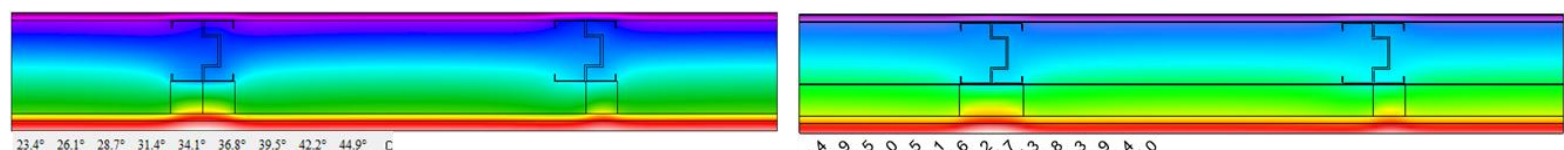

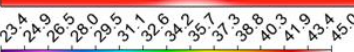

(a) LSF wall n. 1 - Without thermal insulation
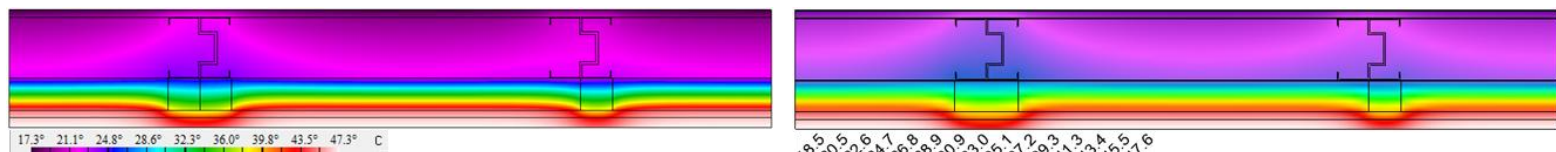

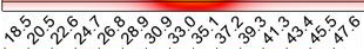

(b) LSF wall n. 2 - With MW in the air-cavity
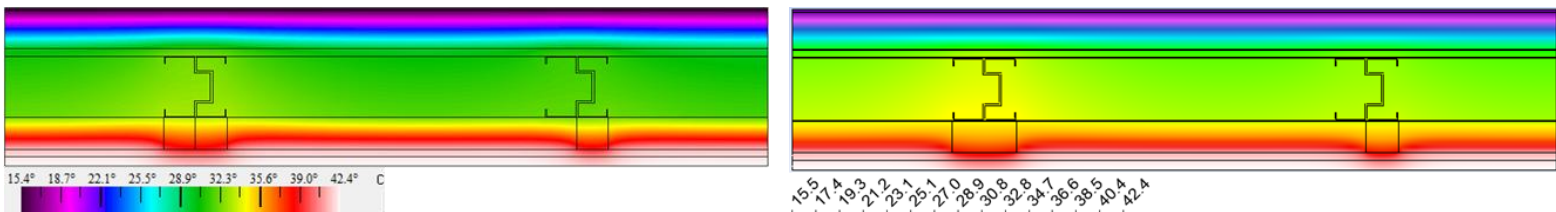

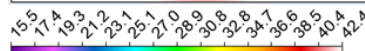

(c) LSF wall n. 3 - With MW and ETICS

Figure 14. Cross-section temperatures predicted by 2D and 3D FEM models. 


\section{Conclusions}

In this work, the thermal transmittance ( $U$-value) of three different LSF walls is experimentally, numerically and analytically evaluated. The experimental measurements were performed using a hot and a cold climatic chambers, and the HFM method. The areaweighted overall $U$-value of the LSF wall was measured using the ASHRAE zone method [28]. 3D FEM-based simulations using ANSYS CFX ${ }^{\circledR}$ and 2D FEM-based simulations using THERM software were carried out to estimate the $U$-value of the different LSF wall configurations. The analytical estimations were based on the ISO 6946 [24] approach (combined method) for building components with inhomogeneous layers. Several verification procedures were performed to ensure the reliability of the experimental measurements, and numerical and analytical approaches, including: $(i)$ a comparison between the measurements of a homogenous XPS wall for which the thermal conductivity of the material is known; (ii) a comparison between the 2D and 3D FEM models and the test cases prescribed in ISO 10211 [31], and also with some simplified LSF wall models with homogeneous layers (i.e., without steel/wood frame); (iii) a comparison between the LSF walls temperature surface distribution predicted by 3D FEM models and IR thermography images; and (iv) comparison between the ISO 6946 [24] analytical approach for building components with inhomogeneous layers and the 2D FEM approach.

The main conclusions of this work can be listed as follows:

- The wood slats allowed to reduce the thermal bridge effect originated by the steel studs, being the thermal transmittance reduction, when there is no thermal insulation, $-26 \%$ and $-10 \%$ for one and two wood slats, respectively.

- Adding $50 \mathrm{~mm}$ of mineral wool to the air-cavity allowed to significantly reduce the overall thermal transmittance of the wall $(-58 \%)$.

- Given the thermal insulation continuity of the ETICS, the steel studs thermal 
bridging effect was significantly reduced, resulting in $U$-values between and near the steel profiles closer to each other. The overall thermal transmittance reduction was $76 \%$ and $-43 \%$ in relation to LSF wall $n .1$ and LSF wall n. 2.

- The analytical ISO 6946 [24] approach (combined method) showed a very good performance for these simple LSF walls, being the difference in relation to the $2 \mathrm{D}$ FEM simulations equal to only $-0.2 \%,+2.6 \%$ and $0.0 \%$ for the LSF walls $n^{\circ} 1,2$ and 3 , respectively.

- Given the simplicity of the tested LSF walls (only vertical steel studs), the accuracy of the $2 \mathrm{D}$ FEM models were similar, or even better, than the one provided by $3 \mathrm{D}$ FEM models.

- The difference between the measured and the predicted values were lower for the surface temperature distributions in comparison with the overall $U$-values.

\section{Acknowledgments}

This work was supported by FEDER funds through COMPETE 2020 - POCI and by FCT in the framework of the project PCMs4Buildings (POCI-01-0145-FEDER-016750 | PTDC/EMS-ENE/6079/2014).

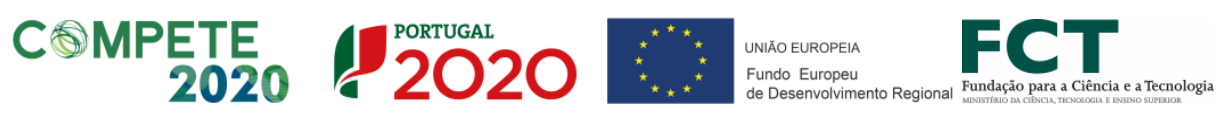

\section{References}

[1] European Union, Directive (EU) 2018/844 of the European Parliament and of the Council of 30 May 2018 amending Directive 2010/31/EU on the energy performance of buildings and Directive 2012/27/EU on energy efficiency, Off. J. Eur. Union. 2018 (2018) 75-91.

[2] P. Santos, L. Simões da Silva, V. Ungureanu, Energy Efficiency of Light-weight Steel- 
framed Buildings, 1st ed., European Convention for Constructional Steelwork (ECCS), Technical Committee 14 - Sustainability \& Eco-Efficiency of Steel Construction, ISBN 978-92-9147-105-8, N. 129, 2012.

[3] N. Soares, P. Santos, H. Gervásio, J.J. Costa, L. Simões da Silva, Energy efficiency and thermal performance of lightweight steel-framed (LSF) construction: A review, Renew. Sustain. Energy Rev. 78 (2017) 194-209.

[4] P. Santos, Chapter 3 - Energy Efficiency of Lightweight Steel-Framed Buildings, in: ENG_HWA_YAP (Ed.), Energy Effic. Build., InTech, Croatia, 2017: pp. 35-60.

[5] P. Santos, C. Martins, L. Simões da Silva, Thermal performance of lightweight steelframed construction systems, Metall. Res. Technol. 111 (2014) 329-338.

[6] C. Kendrick, R. Ogden, X. Wang, B. Baiche, Thermal mass in new build UK housing: A comparison of structural systems in a future weather scenario, Energy Build. 48 (2012) 40-49.

[7] L.T. Rodrigues, M. Gillott, D. Tetlow, Summer overheating potential in a low-energy steel frame house in future climate scenarios, Sustain. Cities Soc. 7 (2013) 1-15.

[8] K. Gregory, B. Moghtaderi, H. Sugo, A. Page, Effect of thermal mass on the thermal performance of various Australian residential constructions systems, Energy Build. 40 (2008) 459-465.

[9] E. Roque, P. Santos, The Effectiveness of Thermal Insulation in Lightweight SteelFramed Walls with Respect to Its Position, Buildings. 7(1) (2017) 1-18.

[10] E. Roque, P. Santos, A.C. Pereira, Thermal and sound insulation of lightweight steelframed façade walls, Sci. Technol. Built Environ. 25 (2019) 156-176.

[11] P. Santos, C. Martins, L. Simoes da Silva, L. Bragança, Thermal performance of lightweight steel framed wall: The importance of flanking thermal losses, J. Build. Phys. 38 (2014) 81-98. 
[12] C. Martins, P. Santos, L. Simoes da Silva, Lightweight steel-framed thermal bridges mitigation strategies: A parametric study, J. Build. Phys. 39 (2016) 342-372.

[13] P. Santos, H. Gervásio, L. Simoes da Silva, A. Gameiro, Influence of climate change on the energy efficiency of light-weight steel residential buildings, Civ. Eng. Environ. Syst. 28 (2011) 325-352.

[14] N. Soares, A.R. Gaspar, P. Santos, J.J. Costa, Multi-dimensional optimization of the incorporation of PCM-drywalls in lightweight steel-framed residential buildings in different climates, Energy Build. 70 (2014) 411-421.

[15] H. Gervásio, P. Santos, L. Simões da Silva, A.M.G. Lopes, Influence of thermal insulation on the energy balance for cold-formed buildings, Adv. Steel Constr. 6 (2010) $742-766$.

[16] A. Craveiro, A. Gameiro Lopes, P. Santos, L. Simões Da Silva, Natural ventilation potential on thermal comfort of a light-steel framing residential building, in: Green Des. Mater. Manuf. Process. - Proc. 2nd Int. Conf. Sustain. Intell. Manuf. SIM 2013, 2013.

[17] P. Santos, L. Simoes da Silva, H. Gervasio, A. Gameiro Lopes, Parametric analysis of the thermal performance of light steel residential buildings in Csb climatic regions, J. Build. Phys. 35 (2011) 7-53.

[18] N. Soares, C. Martins, M. Gonçalves, P. Santos, L. Simões da Silva, J.J. Costa, Laboratory and in-situ non-destructive methods to evaluate the thermal transmittance and behaviour of walls, windows, and construction elements with innovative materials: a review, Energy Build. 182 (2019) 88-110.

[19] ISO 9869, Thermal insulation - Building elements - In-situ measurement of thermal resistance and thermal transmittance, International Organization for Standardization, (2014). 
[20] X. Meng, B. Yan, Y. Gao, J. Wang, W. Zhang, E. Long, Factors affecting the in situ measurement accuracy of the wall heat transfer coefficient using the heat flow meter method, Energy Build. 86 (2015) 754-765.

[21] ISO 8990, Thermal insulation - Determination of steady-state thermal transmission properties - Calibrated and guarded hot box, International Organization for Standardization, (1994).

[22] E. Lucchi, Applications of the infrared thermography in the energy audit of buildings: A review, Renew. Sustain. Energy Rev. 82 (2018) 3077-3090.

[23] M. Gorgolewski, Developing a simplified method of calculating U-values in light steel framing, Build. Environ. 42 (2007) 230-236.

[24] ISO 6946, Building components and building elements — Thermal resistance and thermal transmittance — Calculation methods, International Organization for Standardization, (2017).

[25] L. Zalewski, S. Lassue, D. Rousse, K. Boukhalfa, Experimental and numerical characterization of thermal bridges in prefabricated building walls, Energy Convers. Manag. 51 (2010) 2869-2877.

[26] Y. Li, J. Yao, R. Li, Z. Zhang, J. Zhang, Thermal and energy performance of a steelbamboo composite wall structure, Energy Build. 156 (2017) 225-237.

[27] I.A. Atsonios, I.D. Mandilaras, D.A. Kontogeorgos, M.A. Founti, Two new methods for the in-situ measurement of the overall thermal transmittance of cold frame lightweight steel-framed walls, Energy Build. 170 (2018) 183-194.

[28] ASHRAE, Handbook of Fundamentals, American Society of Heating, Refrigerating and Air-Conditioning Engineers, Atlanta, USA, 2001.

[29] ASTM-C1155-95(Reapproved-2001), Standard Practice for Determining Thermal Resistance of Building Envelope Components from the In-Situ Data, American Society 
for Testing and Materials, (2001).

[30] ASTM-C1046-95(Reapproved-2001), Standard Practice for In-Situ Measurement of Heat Flux and Temperature on Building Envelope Components, American Society for Testing and Materials, (2001).

[31] ISO 10211, Thermal bridges in building construction — Heat flows and surface temperatures - Detailed calculations, International Organization for Standardization, (2017). 